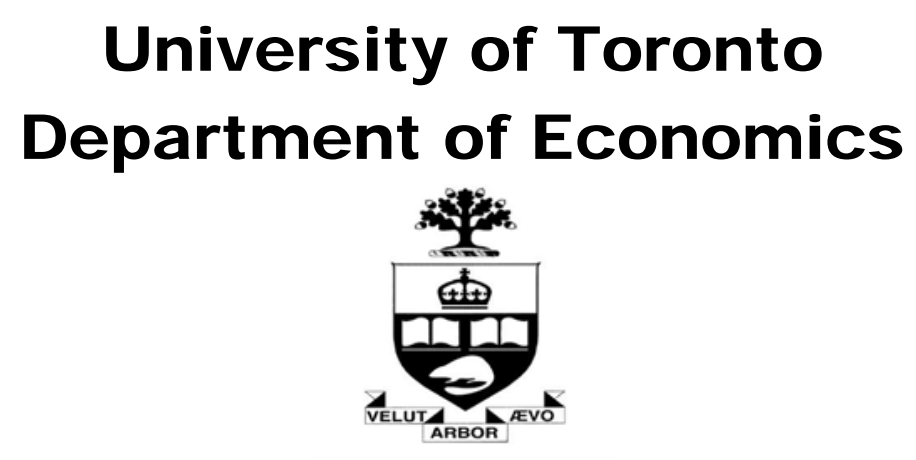

Working Paper 400

Land Use Regulation as a Barrier to Entry: Evidence from the Texas Lodging Industry

By Junichi Suzuki

April 01, 2010 


\title{
Land Use Regulation as a Barrier to Entry: Evidence from the Texas Lodging Industry
}

\author{
Junichi Suzuki* \\ University of Toronto
}

April 1, 2010

\begin{abstract}
I empirically examines the anticompetitive effects of land use regulation by using microdata on midscale chain hotels in Texas. I construct a dynamic entry-exit model of midscale hotel chains. By endogenizing their entry decisions, the model explicitly considers hotel chains' reactions to the stringency of land use regulation. Estimation results indicate that imposing stringent regulation increases cost enough to affect hotel chains' entry decisions. Although hotel chains are the immediate payers of the increased entry cost, incumbents shift a part of their cost increase onto consumers by exploiting their increased market power. (JEL: R3, L1, L5)
\end{abstract}

${ }^{*}$ Department of Economics, University of Toronto. Address: 150 St. George Street Toronto ON, M5S 3G7 Canada. Email: j.suzuki@utoronto.ca. This work was made possible by the facilities of the Shared Hierarchical Academic Research Computing Network (SHARCNET: www.sharcnet.ca). This manuscript is based on the second chapter of my 2009 University of Minnesota Ph.D. dissertation. I am grateful to my advisors, Pat Bajari and Tom Holmes for their patience and advice. I also wish to thank Victor Aguirregabiria, Martin Burda, Kyoo Il Kim, Minjung Park, Amil Petrin and Bob Town for helpful discussions and Yoshifumi Konishi, Julia Thornton and Michael Walrath for giving me detailed comments. Of course, all remaining errors are my own. 
In the U.S., local governments regulate private land use within their boundaries mainly through zoning. Zoning regulates private land use from various aspects, including the purpose of land use or the shape of buildings. These regulations impose additional entry costs on new businesses by forcing them, for example, to use expensive materials (e.g., brick) for the exterior of their buildings or to deviate from a prototype building design. Although business owners can request rezonings or exceptions, these requests need to go through processes that could involve city administration, politics and jurisdiction, and often incur considerable expense.

This paper argues that stringent land use regulation generates a distortion in local business markets by discouraging entry and, as a result, lessening competition. Although people in the legal professions have noticed this anticompetitive effect of land use regulation ${ }^{1}$, it has attracted little attention from economists and few formal analyses have been done. ${ }^{2}$

The goal of this paper is to assess the empirical relevance of this hypothesis using microdata on midscale Texas chain hotels and land use regulation data collected from local municipalities. Note that this paper is not intended to be the final word on land use regulation. This paper focuses on an anticompetitive effect of land use regulation and ignores its other possible benefits and costs. Therefore, the results of this paper are not sufficient per se to make final judgments on land use regulation. When it generates benefits to society through some other channels (e.g., resolves externalities), land use regulation could be beneficial overall, despite the distortion.

Several facts indicate the relevance of this proposed hypothesis to the lodging industry. First, land use regulation appears to be among the major determinants of cost structure, and hence entry decisions of hotels. This industry is capital-intensive ${ }^{3}$ and its primary capital input is undoubtedly buildings. Therefore, it is natural to expect that regulations on buildings have a significant cost impact. If it were not the case, the change of regulation would rarely affect the degree of competition and my hypothesis would have little quantitative importance. Second, competition in this industry is fairly local. Because of the nature of their product, hotels must locate at the place of consumption. Therefore, they cannot sell their product without first having a physical location inside a market. As a result, competitors

\footnotetext{
${ }^{1}$ People in the legal profession have argued that whether municipalities are immune from antitrust liability arising from their local ordinances. See Sullivan (2000) for a summary of these arguments and several influential cases.

${ }^{2}$ One exception is OECD (2008), which coincidentally has a title similar to that of this paper. This report documents several channels through which land use regulation affects competiton and several examples taken from its member countries.

${ }^{3}$ According to an example shown in Powers (1992), the capital cost of a typical 120-room hotel accounts for about 20 percent of its total expenditure. This ratio is about twice as much as that of a suburban restaurant.
} 
are limited to other hotels in the neighborhood and entry decisions of local rivals are among the primary determinants of their market power. If competition were nationwide, entry decisions of local rivals would have little impacts on the intensity of competition, and again, my hypothesis would have little empirical relevance. Third, it appears that people in the lodging industry realize that local land use regulation can act as an entry barrier on their competitors. This is indicated by the following quote:

There's a short answer to why certain hotel developers choose projects encumbered with difficult zoning or environmental challenges. It's because once those hurdles are cleared, they're often left with a hotel with desirable barriers to entry. (Cruz (2003))

My empirical analysis starts with reduced form regressions to assess any correlation between the number of midscale hotels belonging to the six largest, midscale hotel chains and that market's land use regulations. Reduced form regression results are consistent with the prediction of my hypothesis. I next construct a dynamic entry-exit model for hotel chains and apply it to the revenue data. To make the estimation computationally feasible, I employ the two-step method recently developed by Bajari et al. (2007). As a last step, by using the structural parameter estimates, I simulate the entry-exit decisions of the hotel chains under three different policies and observe the changes in market structure.

One of the major obstacles for empirical studies of land use regulation is its quantification. Complicated rules and the prevalence of local discretion in the actual implementation of these regulations indicate that no single index is a definitive measure. Acknowledging this difficulty, I employ various measures based on the written survey collected and summarized by Gyourko et al. (2008). Some of these measures are based on institutional features (e.g., the presence of particular regulations) while some other measures are based on the results of actual implementation (e.g., the average time length to obtain a building permit).

Reduced form regressions indicate that markets under stringent land use regulation tend to have fewer hotels. However, these regressions fail to separately identify the cost impact of land use regulation from its impact on local travel demand. Land use regulation could affect local travel demand by, for example, preserving some view that attracts tourists or discouraging constructions of commercial buildings that draw business travelers. When stringent regulation decreases local travel demand overall, this demand-side effect can solely generate the observed negative correlation between the stringency of land use regulation and the number of entries. Therefore, the observed negative correlation does not necessarily imply that land use regulation increases entry cost of hotels. To avoid this drawback, I need to pursue structural estimation. 
I consider a dynamic entry-exit model of hotel chains in which they maximize their expected profits by choosing the number of hotels they open or close in a local market every period. The revenue of one hotel in a chain is a function of market-specific revenue shifter, chain-specific revenue shifter and the number of other hotels present in the same market. Since a new hotel cannibalizes the revenue of other hotels in the same chain, the marginal revenue of opening an additional hotel monotonically decreases. The costs hotel chains incur consist of sunk-entry cost, operating cost and exit cost. While the sunk-entry cost and exit cost are incurred only at the time of opening and closing, respectively, operating cost is incurred at every period until the hotel closes down. I assume that a chain's sunk-entry cost and exit cost are stochastic and their actual sizes are only observable to this chain only. Therefore hotel chains' entry and exit decisions are based on their beliefs about their competitors' entry-exit decisions. In a Markov Perfect equilibrium, these beliefs must be consistent with the actual entry-exit decisions of rival chains.

Estimation consists of three stages. I first estimate the parameters of a hotel-level revenue function. Exploiting the longitudinal structure of the dataset, I can identify market-specific revenue shifters that may be attributable to both observable and unobservable time-invariant factors. Taking these estimates as given, I next recover market-specific cost shifters by finding a set of parameters that rationalizes both the revenue function estimates and the observed entry decisions over time. To take into account the interacting entry-exit decisions of competing hotel chains while maintaining computational burden, I employ the estimation method developed by Bajari et al. (2007). Finally, from the recovered market-specific cost parameter estimates and the land use regulation indices, I draw a statistical inference that stringent land use regulation increases the market-specific cost shifters by running regressions.

The main finding of this paper is the quantitative significance of the proposed hypothesis. First, estimation results indicate that imposing stringent regulation increases both operation costs and sunk-entry costs enough to affect a hotel chain's decisions about entering a market. Second, although they are the immediate payers of the increased entry cost, incumbents shift a part of their cost increase onto consumers by exploiting their market power.

This paper makes several contributions to the existing literature. First, this paper is among the first to study the impacts of land use regulation on local business markets. The role of land use regulation has been a main concern of urban economics and numerous empirical studies have been conducted in the past. ${ }^{4}$ The focus of these studies is considerably broad, including land price (McMillen and McDonald (1991b)), land development (Wu and

\footnotetext{
${ }^{4}$ For a survey of empirical studies in this area, see Fischel (1989), Pogodzinski and Sass (1991), Evans (1999) and Quigley (2007). Regional Science and Urban Economics published a special issue featuring studies of land use regulation. For the summary of these papers, see Cheshire and Sheppard (2004).
} 
Cho (2007)), density (McConnell et al. (2006)) and housing markets. ${ }^{5}$ Nonetheless, its impact on local business has not attracted much attention from economists. A few notable exceptions such as Kunce et al. (2002), Ridley et al. (2010) and Nishida (2010) rely on binary data that tell if a particular location is zoned or not. In contrast, this paper uses several indices that measure the stringency of land use regulation from various aspects.

Second, in relation to the literature on empirical industrial organization, this paper belongs to the large literature on firms' entry decisions that originated from classical papers such as Bresnahan and Reiss (1990) and Berry (1992). ${ }^{6}$ Among others, this paper is perhaps most closely related to Ryan (2009). In his paper, Ryan estimates a dynamic entry-exit model of cement plants and evaluates the welfare consequences of a change in environmental regulation in the Portland cement industry. While Ryan relies on the intertemporal difference of the industrial structure for identification, this paper attempts to exploit cross-market differences in land use regulation by employing indices that directly measure the stringency of land use regulation in each market.

The rest of the paper proceeds as follows: Section 2 provides an overview of land use regulation for the Texas lodging industry. Section 3 summarizes the data used in the empirical analysis while Section 4 presents the results of the reduced form regressions. Section 5 describes the empirical model used for structural estimation. Section 6 explains the estimation method, and Section 7 presents the estimation results. Section 8 demonstrates the results of counterfactual experiments, and Section 9 concludes.

\section{Land Use Regulation for the Texas Lodging Industry}

The basis of the current zoning ordinances in the U.S. goes back to 1926 when the U.S. Department of Commerce drafted the Standard State Zoning Enabling Act (SZEA), which has become a prototype of state statutes on zoning ordinance. ${ }^{7}$ The state of Texas adopted its version of the SZEA in 1927. The Texas statute grants municipalities authority over the legislation and implementation of zoning. According to the Texas statute, the purpose of zoning is "promoting the public health, safety, morals, or general welfare and protecting and preserving places and areas of historical, cultural, or architectural importance and

\footnotetext{
${ }^{5}$ A skyrocketing of housing prices in large metropolitan areas in 2000s prompted studies about the effects of land use regulation in housing markets. For example, a series of empirical studies by Glaeser and his coauthors (Glaeser et al. (2005a), Glaeser et al. (2005b), Glaeser and Ward (2009)) claim that a significant portion of increasing housing prices is attributable to stringent land use regulation.

${ }^{6}$ See Berry and Reiss (2007) for a recent survey in this area.

${ }^{7}$ This section is mainly based on Fischel (1985) for general institutional knowledge of land use regulation and Nance (2006) for information specific to Texas. Other sources I found helpful include O'Flaherty (2005) and O'Sullivan (2000).
} 
significance." 8

Implementation of zoning generally involves several departments of a municipal office. Although its process varies from municipality to municipality, its basic structure is similar. Figure 1 illustrates an example of the administrative process developers need to undergo to obtain building permits. Developers planning to construct new commercial buildings within the boundaries of a local government (Fredericksburg, Texas) first need to speak with city officials in several departments in order to discuss possible problems with the building plans. If the plans do not violate current zoning restrictions, the process is quite simple. For example, developers submit their applications to the Planning and Zoning Commission, which consists of nine members appointed by the mayor. Unless a disagreement is discovered between the submitted plan and the current zoning ordinance, the commission usually approves the plan. Once approved, developers submit a blueprint of their construction to the building department, which ensures the submitted plan meets building codes. Once it is confirmed that the plans comply with building codes, building permits are issued to the developers.

However, if construction plans do not conform with current zoning laws, developers have three choices. They can (1) request a rezoning, (2) request an exception to current zoning, called a variance or (3) withdraw their plans. The procedure for rezoning is different from that of a variance. If rezoning requires amending the current zoning laws while issuing a variance does not. Developers' requests for rezoning are sent to the Planning and Zoning Commission. After holding a public hearing, the commission sends its recommendation on the requested zoning to the City Council. The City Council makes a final decision after holding the second public hearing. In contrast, requests for variances are sent to the Zoning Board of Adjustment (ZBA), which consists of five regular members and three alternate members appointed by the City Council. The ZBA makes its decision after holding a public hearing. Unlike rezoning, decisions of the ZBA are final and the City Council is not involved in the process.

\section{Data}

\subsection{Texas Hotel Data}

The main data source of this study, Hotel Occupancy Tax Receipts, is provided by the Texas Comptroller of Public Accounts. ${ }^{9}$ This quarterly data set provides the sale of every single hotel in Texas, as well as other hotel specific information including names, street addresses

\footnotetext{
${ }^{8}$ Texas Statutes, Local Government Code, Chapter 211.001.

${ }^{9}$ Other studies using this dataset include Chung and Kalnins (2001), Kalnins (2004) and Conlin and Kadiyali (2006).
} 


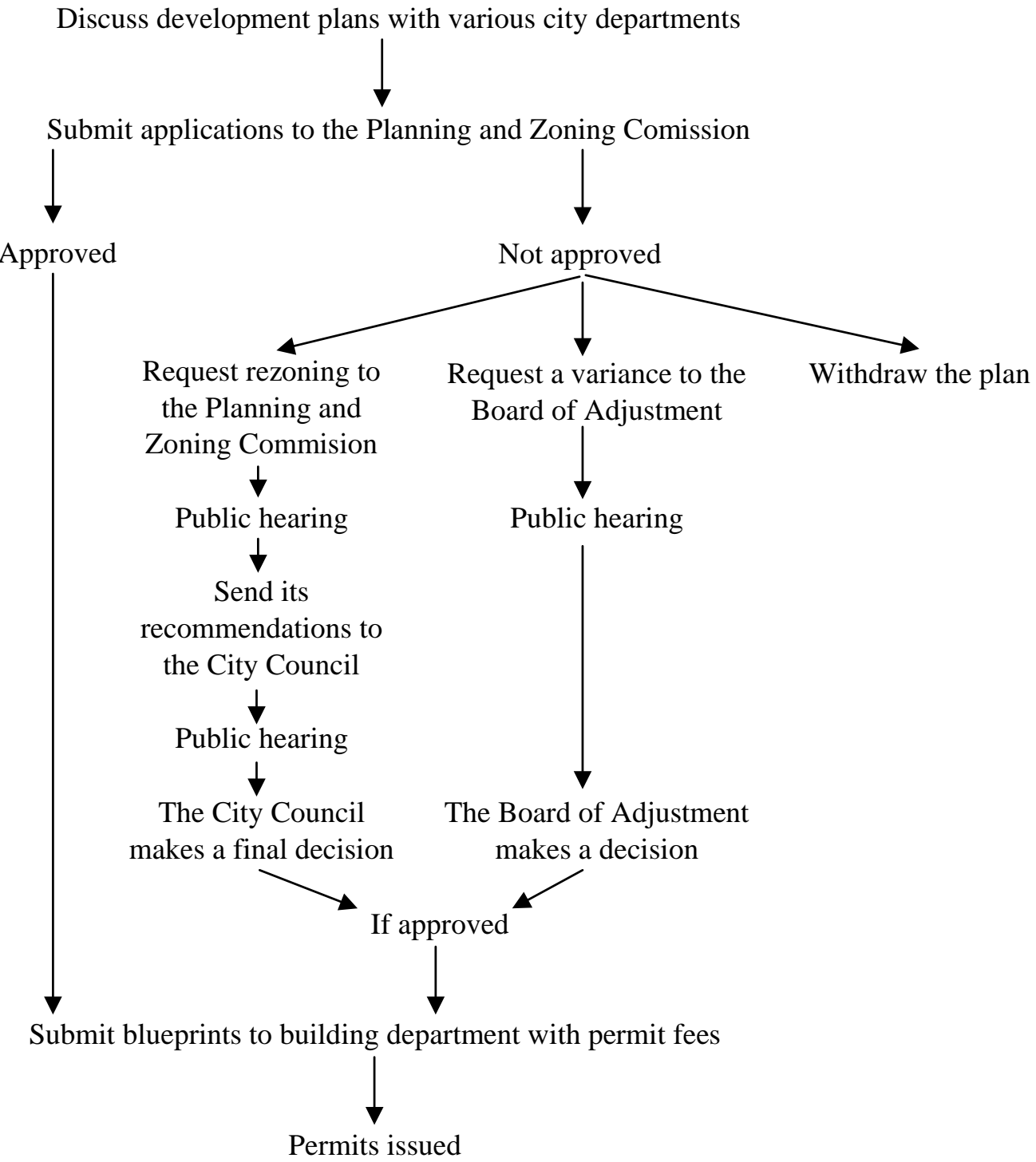

Figure 1: Implementation of Zoning Ordinance: Fredericksburg, Tex. 
and numbers of rooms. In addition, I recover each hotel's brand affiliation, if any, by looking for particular brand names (e.g., Best Western) in the name of each hotel. To increase the accuracy of this process, I rely on other sources, such as AAA Tourbook, Directory of Hotel 85 Lodging Companies and various hotel directories provided by the hotel chains themselves. The sample period of this data set is from the first quarter of 1990 through the last quarter of 2005. By exploiting the identification code that is unique and permanent for every hotel, I construct an unbalanced panel data set. A notable advantage of this data set is the reliability of its sales data. The original purpose of this data set was to determine the amount of the hotel occupancy tax to be collected by hotel owners and passed on to the state government. Because of this nature, misreporting is unlawful and can be considered tax evasion.

\subsection{Measurement of Land Use Regulation}

This study employs the indices developed by Gyourko et al. (2008) as measures for the stringency of land use regulation. Based on a written survey collected from 2,649 local governments in the U.S., Gyourko and his coauthors construct eleven subindices that measure the stringency of residential land use regulation from various angles. Among these indices, I use seven subindices that show considerable variations among the counties in my sample. ${ }^{10}$ For all indices, large values imply stringent regulation. Table 1 shows the list of these indices and provides a brief description of each index. The precise definitions of these seven indices are found in Gyourko et al. (2008). ${ }^{11}$

\subsection{Other Data}

Demographic data is from the decennial census and the Regional Economics Information System provided by the Bureau of Economic Analysis. This demographic data includes population, per capita personal income and area. Local business activity data is obtained from County Business Patterns provided by the Census Bureau. This business data includes the number of employees and the number of establishments. I also construct dummy variables for each county's access to the Interstate Highway System along with their access to commercial airports. To do so, I use road maps and websites of commercial airports, respectively. Construction cost data comes from Means Square Foot Costs provided by RSMeans.

\footnotetext{
${ }^{10}$ The subindices not used here due to their little variation between the counties in my sample are (1) a measure for state level political pressure, (2) a measure for the influence of state court, (3) the involvement of the local assembly in the implementation of land use regulation and (4) the presence of supply restriction.

${ }^{11}$ For some indices, the names used in this paper are slightly different from those used in the original paper for simplicity. These indices are Political Pressure (The Local Political Pressure Index), Zoning Approval (The Local Zoning Approval Index) and Project Approval (Local Project Approval Index). The names in parentheses are those used in Gyourko et al. (2008).
} 
Table 1: Description of Land Use Regulation Indices

\begin{tabular}{ll}
\hline \hline Name & Description \\
\hline Political Pressure & $\begin{array}{l}\text { Summarizes subjective impressions of the influ- } \\
\text { ence of various political groups (council, pressure } \\
\text { groups, citizens). Normalized so that its mean and } \\
\text { its standard deviation become zero and one, re- } \\
\text { spectively. }\end{array}$ \\
Zoning Approval & $\begin{array}{l}\text { The number of local government bodies from } \\
\text { which projects that request zoning change need to } \\
\text { obtain approvals. }\end{array}$ \\
Project Approval & $\begin{array}{l}\text { The number of local government bodies from } \\
\text { which projects that request NO zoning change } \\
\text { need to obtain approvals. }\end{array}$ \\
Density Restriction & $\begin{array}{l}\text { Indicates if local governments have minimum lot } \\
\text { size requirements of one acre or more. }\end{array}$ \\
Open Space & $\begin{array}{l}\text { Indicates if developers have to provide open space } \\
\text { for the public. }\end{array}$ \\
Exactions & $\begin{array}{l}\text { Indicates if developers have to incur the cost of } \\
\text { additional infrastructure attributable to their de- } \\
\text { velopments. }\end{array}$ \\
The average number of months for which develop- \\
The need to wait to obtain building permits before \\
starting construction.
\end{tabular}

Notes: See Gyourko et al. (2008) for the construction of these indices. 
Table 2: Midscale Chain Hotels in Texas

\begin{tabular}{ll}
\hline \hline \multicolumn{1}{c}{ Companies } & \multicolumn{1}{c}{ Brands } \\
\hline & \\
Best Western & Best Western \\
Cendant & Amerihost, Howard Johnson, Ramada \\
Choice Hotels & Clarion, Comfort Inn, Quality Inn, Sleep Inn \\
Hilton Hotels & Hampton Inn \\
InterContinental & Candlewood, Holiday Inn, Holiday Inn Express \\
La Quinta & Baymont Inn, La Quinta Inn \\
& \\
\hline
\end{tabular}

Notes: The number of hotels listed is as of the first quarter of 2005.

\subsection{Market Definition}

In the rest of this study, I limit my focus to local competition between midscale chain hotels. To determine midscale brands, I follow a scale constructed by Smith Travel Research, an independent consulting firm specializing in the lodging industry. Among the hotel chains owning these brands, I consider the six major chains. Table 2 lists the names of these hotel chains and their midscale brands in my sample as of the first quarter of 2005. These seven chains account for about 90 percent of the number of midscale chain hotels in Texas.

This narrowed focus is beneficial since it makes my empirical analysis considerably neat without losing the essential aspects of local lodging markets. First, as indicated by Mazzeo (2002), the lodging market is highly segmented by service grades, and competition is stronger within segments rather than between segments. For example, Expedia.com, an on-line travel agency, hits 103 options for a one night stay in Austin, Texas. These choices range from a room in a budget motel for $\$ 45$ a night to a room in a luxury hotel for $\$ 259$. High grade hotels often provide restaurants, room service and fitness centers in addition to nicely decorated rooms. In contrast, low grade hotels, often called "no frill" hotels, merely provide clean and safe rooms for a low price. These two types of hotels belong to different segments and do not appear to compete against each other. Second, among the three segments of hotels (economy, midscale and upscale), the midscale segment is the largest category in terms of both the number of hotels and the number of rooms. Third, chain hotels have been the primary players in this industry. In 2005, in Texas, chain hotels account for 37 percent of the total number of hotels, 63 percent of the total rooms and 75 percent of total sales. The apparently high ratio of non-chain properties is unlikely to be problematic for my analysis as these non-chain properties consist of independent hotels, and various businesses that are 


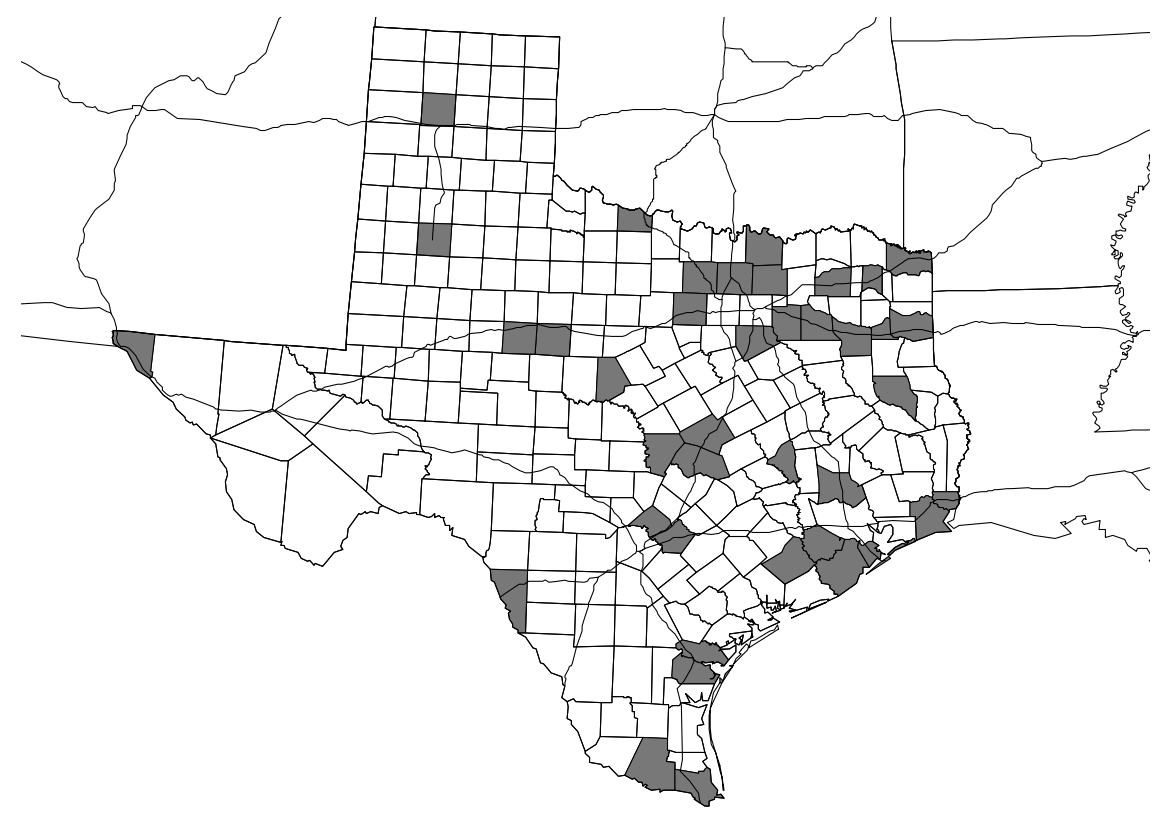

Figure 2: Graphical Representation of Sample Counties (Dark areas)

not conventionally considered hotels. ${ }^{12}$ Independent hotels are generally considered to be in the economy segment, and because services of these other businesses are different from those of the midscale hotels, their presence should not be important for the business of midscale hotels.

For this study, I consider a county as a single local market since more data is available at the county level, its shape is relatively uniform in Texas and its border has been fixed overtime. Among the 254 counties in Texas, my sample consists of 40 counties that survive the following three screenings: (1) counties must provide land use regulation indices, (2) counties must have undergone at least four opens/closures of the midscale chain hotels during the sample period and (3) counties must not be the flagship counties of the four largest MSAs. ${ }^{13}$ Figure 2 shows the geographical distribution of these 40 counties.

\subsection{Summary Statistics}

Table 3 reports the summary statistics of variables that describe the forty markets in my sample. The median market has seven midscale chain hotels or 573 rooms, and earns about

\footnotetext{
${ }^{12}$ Texas statutes (Tax Code, Chapter 156.001) define a hotel as "a building in which members of the public obtain sleeping accommodations for consideration". Ranches, cabins and campgrounds all satisfy this definition. Although I remove properties that are obviously not hotels from my sample, there are significant number of properties whose actual categories are unclear.

${ }^{13}$ These counties are Bexar (San Antonio), Dallas (Dallas-Fort Worth), Harris (Houston), Tarrant (DallasFort Worth) and Travis (Austin).
} 
more than two million dollars for one quarter. These numbers imply that each hotel has eighty-two rooms and each of these rooms earns forty-two dollars for a night. Table 3 also shows a considerable size variation between the markets in my sample. In terms of population, the size of the market at the sample third quartile is more than four times larger than that of the market at the sample first quartile. About 80 percent of the markets in this sample have access to an Interstate Highway and about one third of them have access to commercial airports.

Descriptive statistics of the land use regulation indices are hard to interpret because of their lack of units. Instead, I observe the relationship between market size and these indices by constructing a correlation matrix shown in Table $4 .{ }^{14}$ First, land use regulation tends to be more stringent in markets of larger population size. Out of the seven indices this paper uses, four of them show statistically significant positive correlation with population. Second, four out of the five significant correlations between these seven subindices are positive, suggesting that local governments implement each individual policy according to certain underlying attitudes such as pro-development or pro-environment.

\section{Reduced Form Analysis}

This section examines an empirical relationship between the stringency of land use regulation and two endogenous variables, equilibrium quantity and equilibrium prices by running simple reduced-form regressions. The proxy for the equilibrium quantity is the number of midscale chain hotels ${ }^{15}$. The proxy for the equilibrium price is revenue per room. ${ }^{16}$ The regressors consist of the land use regulation indices and various controls that characterize local markets. I use ordered logit for the number of hotels and ordinary least squares (OLS) for the revenue per room. For both estimations, I employ the robust standard errors to take into account the possible heteroskedasticity in error terms.

The impact of stringent land use regulation on the equilibrium quantity and equilibrium price of local lodging markets is not obvious. According to my hypothesis, stringent land use regulation decreases supply of lodging services by increasing the cost for hotels. However, its impact on demand is ambiguous. On one hand, stringent regulation could decrease local travel demand by discouraging some businesses to come, hence decreasing demand

\footnotetext{
${ }^{14}$ When counties in my sample contain more than one municipality and land use regulation indices are available for both municipalities, I use the weighted average of the original indices of these municipalities for my analysis. City population is used as weights.

${ }^{15}$ The regression using the total number of rooms as its dependent variable generates similar results.

${ }^{16}$ Increase in revenue per room does not necessarily mean increase in prices since not only price but also occupancy rates (the number of rooms sold over the total number of rooms) affect the revenue per room.
} 
Table 3: Summary Statistics of Markets in the Sample

\begin{tabular}{|c|c|c|c|c|c|}
\hline & Mean & Std.Dev. & P25 & $\overline{\mathrm{P} 50}$ & P75 \\
\hline \multicolumn{6}{|l|}{ Midscale Hotels } \\
\hline \# of Hotels & 9.00 & 6.06 & 1.00 & 7.00 & 13.50 \\
\hline \# of Rooms & 790.28 & 628.00 & 255.00 & 573.00 & $1,206.00$ \\
\hline Quarterly Sales (in million) & 3.13 & 2.88 & .79 & 2.19 & 4.93 \\
\hline \multicolumn{6}{|l|}{ Indices for Land Use Regulation } \\
\hline Political Pressure & 0.10 & 0.98 & -0.73 & 0.08 & 0.69 \\
\hline Exactions & 0.88 & 0.29 & 0.92 & 1.00 & 1.00 \\
\hline Open Space & 0.43 & 0.45 & 0.00 & 0.31 & 0.97 \\
\hline Approval Delay & 3.20 & 1.77 & 1.69 & 2.94 & 3.99 \\
\hline Zoning Approval & 2.02 & 0.72 & 2.00 & 2.00 & 2.48 \\
\hline Project Approval & 1.15 & 0.73 & 0.69 & 1.11 & 1.91 \\
\hline Density Restriction & 0.27 & 0.39 & 0.00 & 0.00 & 0.50 \\
\hline \multicolumn{6}{|l|}{ Other County Characteristics } \\
\hline Population (in thousand) & 200.06 & 190.50 & 61.96 & 118.34 & 278.02 \\
\hline Area (in sq mi) & 869.39 & 255.03 & 784.22 & 903.53 & 945.31 \\
\hline Per Capita Income (in thousand) & 27.97 & 5.49 & 24.94 & 27.60 & 30.89 \\
\hline \# of Establishments (in thousand) & 3.87 & 3.38 & 1.07 & 2.96 & 5.81 \\
\hline Employments (in thousand) & 57.49 & 53.06 & 14.52 & 42.29 & 89.41 \\
\hline MSA Dummy & 0.75 & 0.44 & 0.50 & 1.00 & 1.00 \\
\hline Airport Dummy & 0.33 & 0.47 & 0.00 & 0.00 & 1.00 \\
\hline Interstate Highway Dummy & 0.78 & 0.42 & 1.00 & 1.00 & 1.00 \\
\hline Construction Price Index & 0.78 & 0.03 & 0.76 & 0.78 & 0.80 \\
\hline
\end{tabular}

Notes: $\mathrm{N}=40$. All data are as of the first quarter of 2005. Land use regulation index becomes higher as it becomes more stringent. Hotel data are from Hotel Occupancy Tax Receipts. Land use regulation indices are from Gyoruko et al. (2008). All other county data are from County Business Patterns, Regional Economics Information System, PSMeans and road maps. See Section III for details. 
Table 4: Correlation Matrix between Market Size and Land Use Regulation Indices

\begin{tabular}{|c|c|c|c|c|c|c|c|c|}
\hline & $(1)$ & $(2)$ & $(3)$ & (4) & $(5)$ & (6) & $(7)$ & (8) \\
\hline (1) ln Population & 1.00 & 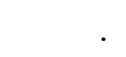 & . & & . & & . & \\
\hline (2) Political Pressure & $0.42^{* *}$ & 1.00 & . & & . & & & \\
\hline (3) Exactions & -0.10 & 0.08 & 1.00 & & . & & & \\
\hline (4) Open Space & $0.46^{* *}$ & $0.50^{* *}$ & 0.18 & 1.00 & 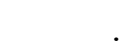 & & & \\
\hline (5) Approval Delay & $0.50^{* *}$ & 0.23 & 0.19 & $0.34^{* *}$ & 1.00 & & & \\
\hline (6) Zoning Approval & 0.07 & 0.10 & 0.02 & 0.12 & -0.20 & 1.00 & & \\
\hline (7) Project Approval & $0.37^{* *}$ & 0.22 & -0.25 & $0.35^{* *}$ & $0.27^{*}$ & -0.26 & 1.00 & \\
\hline (8) Density Restriction & 0.10 & 0.02 & $-0.42^{* *}$ & -0.01 & 0.14 & -0.14 & 0.21 & 1.00 \\
\hline
\end{tabular}

Notes: $\mathrm{N}=40$. See Table 2 for the definitions of abbreviations of the land use regulation indices. Correlation coefficients with ${ }^{* *}$ and ${ }^{*}$ are statistically significant at the five and ten percent level, respectively.

for business travel. On the other hand, stringent land use regulation could increase local travel demand by preserving a particular local environment (e.g., nice views or clean water) that is attractive to either leisure travelers or certain industries. Therefore, the standard supply-demand framework makes the following ambiguous prediction. When stringent land use regulation increases local travel demand overall, the equilibrium price increases while the change in equilirbrium quantity is indeterminate. In contrast, when stringent land use regulation decreases local travel demand overall, the equilibrium quantity decreases while the change in equilibrium quantity is indeterminate.

Table 5 and 6 report the estimates of these reduced-form functions based on the data as of the first quarter of 2005. I estimate these regressions under various specifications to observe the change of estimates as more indices are added to the regressors. First, the reduced form functions fit both the quantity data and the price data well. The regression results show that our control variables explain about one third of the variation of the equilibrium quanatity, and adding land use regulation indices to the regressors increases $R^{2}$ by about eight percentage points. In contrast, the same control variables explain less than 27 percent of the variation observed in the equilibrium prices while adding land use regulation indices increases $R^{2}$ by 18 percentage points.

Second, parameter estimates were mostly consistent with my hypothesis. The column (8) of Table 5 indicate that the paramete for Project Approval is statistically significant at ten percent level. Its negative sign indicates that stringent regulation decreases the number of hotels. Consider an imaginary market whose characteristics are equal to the sample median 
values. My estimates indicate that this market is expected to have 5.9 hotels. When the above index (i.e., Project Approval) exogenously shifts to the sample first quartile level, the expected number of hotels increases to 6.6. In contrast, when these indices exogenously shift to the sample third quartile level, the corresponding number decreases to 4.8. The column (8) of Table 6 indicate that parameter estimates for two indices (Open Space and Project Approval) were statistically significant at ten percent level and their signs are consistent with my hypothesis. According to these estimates, loweing these two indices to the first quartile level from the median level decreases revenue-per-room by 15 percent while increasing them to the third quartile level increases it by 35 percent.

The results above suggest some impact of land use regulation on the entry-exit decisions of the chain hotels and its consequence on equilibrium prices. Nonetheless, these results do not suffice to verify my hypothesis that stringent land use regulation lessens competition in local lodging markets by erecting a barrier to entry. These estimates do not tell if these observed correlations come from either the demand side or the supply side. As discussed above, these correlations can be the consequence of demand decrease caused by stringent land use regulation and the supply side might have nothing to do with it. To identify these two channels separately from the data, I need to rely on a model and estimate its structural parameters.

\section{The Dynamic Entry-Exit Model of Hotel Chains}

In this section I construct a dynamic entry-exit model where $N$ hotel chains may operate multiple hotels in a local market. At the beginning of each period, each chain simultaneously decides whether it opens a new hotel or closes its existing hotels, if any. Both opening a new hotel and closing an existing hotel incur some sunk cost while operating existing hotels incur operation costs. The presence of hotels operated by rival chains affect chain $i$ 's entry and exit decision through their impacts on the revenue of hotels belonging to chain $i$.

\subsection{State Space}

Denote each chain by $i \in\{1, \ldots ., N\}$ and each period by $t \in\{1,2, . ., \infty\}$. Each chain operates at most seven hotels in a market. ${ }^{17} \mathrm{~A}$ common state at period $t$ consists of (i) a vector of the number of hotels operated by each chain $\mathbf{h}_{\mathbf{t}}=\left(h_{1 t}, h_{2 t}, \ldots, h_{N t}\right) \in\{0,1, \ldots, 7\}^{N}$ and (ii) a vector of market-specific characteristics (e.g., population) $\mathbf{x}_{\mathbf{t}} \in X \subset \mathbb{R}^{L}$. This common state is observable to both hotel chains and econometricians. Denote this common state variable

\footnotetext{
${ }^{17}$ This upper limit is hardly restrictive. During the sample period, only one hotel chain hits this limit.
} 
Table 5: Ordered Logit Estimates

\begin{tabular}{|c|c|c|c|c|c|c|c|c|}
\hline & \multicolumn{8}{|c|}{ Dep. Var. = Number of Midscale Hotels } \\
\hline & $(1)$ & $(2)$ & $(3)$ & $(4)$ & $(5)$ & $(6)$ & $(7)$ & $(8)$ \\
\hline \multirow[t]{2}{*}{ Population } & -1.960 & -2.385 & -2.538 & -2.887 & -2.280 & -2.946 & -4.434 & -4.588 \\
\hline & $(2.637)$ & $(2.856)$ & $(3.323)$ & $(3.038)$ & $(2.994)$ & $(3.302)$ & $(3.226)$ & $(3.247)$ \\
\hline \multirow[t]{2}{*}{ \# of Establishments } & 6.701 & 7.593 & 7.804 & 8.044 & 9.450 & 10.242 & 11.647 & 11.817 \\
\hline & $(3.253)$ & $(3.765)$ & $(4.469)$ & $(4.071)$ & $(5.390)$ & $(6.053)$ & $(5.670)$ & $(5.687)$ \\
\hline \multirow[t]{2}{*}{ Political Pressure } & & -0.392 & -0.408 & -0.567 & -0.702 & -0.856 & -0.738 & -0.741 \\
\hline & & $(0.387)$ & $(0.445)$ & $(0.691)$ & $(1.150)$ & (1.308) & $(2.026)$ & $(2.232)$ \\
\hline \multirow[t]{2}{*}{ Exactions } & & & -0.302 & -0.427 & 1.418 & 1.493 & 1.852 & 1.846 \\
\hline & & & $(2.122)$ & $(1.947)$ & $(0.527)$ & $(2.247)$ & $(1.325)$ & $(1.292)$ \\
\hline \multirow[t]{2}{*}{ Open Space } & & & & 1.019 & -2.023 & -1.583 & -1.687 & -1.734 \\
\hline & & & & $(1.016)$ & $(1.091)$ & $(0.624)$ & $(0.578)$ & $(0.543)$ \\
\hline \multirow[t]{2}{*}{ Approval Delay } & & & & & -2.592 & -2.271 & -0.636 & -0.658 \\
\hline & & & & & $(1.454)$ & (1.008) & $(0.719)$ & $(1.587)$ \\
\hline \multirow[t]{2}{*}{ Zoning Approval } & & & & & & 0.989 & -2.207 & -0.849 \\
\hline & & & & & & $(0.461)$ & $(1.191)$ & $(0.717)$ \\
\hline \multirow[t]{2}{*}{ Project Approval } & & & & & & & -1.571 & -2.144 \\
\hline & & & & & & & $(0.832)$ & $(1.186)$ \\
\hline \multirow[t]{2}{*}{ Density Restriction } & & & & & & & & -0.293 \\
\hline & & & & & & & & $(0.875)$ \\
\hline R-squared & 0.331 & 0.336 & 0.336 & 0.341 & 0.370 & 0.389 & 0.413 & 0.414 \\
\hline
\end{tabular}

Notes: $\mathrm{N}=40$. See Table 2 for the meaning of abbreviations for land use regulation indices. Standard errors are in parentheses. Estimates and standard errors for other control variables are suppressed. Other control variables include per capita income, area, construction price index, rural land prices and dummy variables for MSA, access to commercial airports and Interstate Highway. 
Table 6: OLS Estimates

\begin{tabular}{|c|c|c|c|c|c|c|c|c|}
\hline & \multicolumn{8}{|c|}{ Dep. Var. = Log of Revenue Per Room } \\
\hline & (1) & (2) & (3) & $(4)$ & $(5)$ & (6) & (7) & (8) \\
\hline Population & $\begin{array}{c}-0.116 \\
(0.451)\end{array}$ & $\begin{array}{c}-0.111 \\
(0.461)\end{array}$ & $\begin{array}{c}-0.143 \\
(0.444)\end{array}$ & $\begin{array}{c}-0.221 \\
(0.402)\end{array}$ & $\begin{array}{c}-0.269 \\
(0.416)\end{array}$ & $\begin{array}{c}-0.262 \\
(0.408)\end{array}$ & $\begin{array}{c}-0.124 \\
(0.427)\end{array}$ & $\begin{array}{l}-0.143 \\
(0.437)\end{array}$ \\
\hline \# of Establishments & $\begin{array}{c}0.191 \\
(0.541)\end{array}$ & $\begin{array}{c}0.175 \\
(0.562)\end{array}$ & $\begin{array}{c}0.223 \\
(0.544)\end{array}$ & $\begin{array}{c}0.282 \\
(0.486)\end{array}$ & $\begin{array}{c}0.295 \\
(0.503)\end{array}$ & $\begin{array}{c}0.295 \\
(0.512)\end{array}$ & $\begin{array}{c}0.186 \\
(0.525)\end{array}$ & $\begin{array}{c}.208 \\
(0.539)\end{array}$ \\
\hline Political Pressure & & $\begin{array}{c}0.014 \\
(0.040)\end{array}$ & $\begin{array}{c}0.013 \\
(0.041)\end{array}$ & $\begin{array}{l}-0.036 \\
(0.047)\end{array}$ & $\begin{array}{c}-0.035 \\
(0.050)\end{array}$ & $\begin{array}{l}-0.034 \\
(0.051)\end{array}$ & $\begin{array}{l}-0.051 \\
(0.040)\end{array}$ & $\begin{array}{l}-0.051 \\
(0.041)\end{array}$ \\
\hline Exactions & & & $\begin{array}{l}-0.132 \\
(0.195)\end{array}$ & $\begin{array}{l}-0.222 \\
(0.202)\end{array}$ & $\begin{array}{l}-0.228 \\
(0.199)\end{array}$ & $\begin{array}{l}-0.231 \\
(0.204)\end{array}$ & $\begin{array}{l}-0.144 \\
(0.208)\end{array}$ & $\begin{array}{l}-0.182 \\
(0.234)\end{array}$ \\
\hline Open Space & & & & $\begin{array}{c}0.307 \\
(0.136)\end{array}$ & $\begin{array}{c}0.296 \\
(0.151)\end{array}$ & $\begin{array}{c}0.298 \\
(0.155)\end{array}$ & $\begin{array}{c}0.290 \\
(0.153)\end{array}$ & $\begin{array}{c}0.290 \\
(0.156)\end{array}$ \\
\hline Approval Delay & & & & & $\begin{array}{c}0.071 \\
(0.177)\end{array}$ & $\begin{array}{c}0.061 \\
(0.172)\end{array}$ & $\begin{array}{l}-0.036 \\
(0.163)\end{array}$ & $\begin{array}{l}-0.035 \\
(0.163)\end{array}$ \\
\hline Zoning Approval & & & & & & $\begin{array}{l}-0.015 \\
(0.094)\end{array}$ & $\begin{array}{c}0.036 \\
(0.084)\end{array}$ & $\begin{array}{c}0.032 \\
(0.088)\end{array}$ \\
\hline Project Approval & & & & & & & $\begin{array}{c}0.164 \\
(0.093)\end{array}$ & $\begin{array}{c}0.163 \\
(0.095)\end{array}$ \\
\hline Density Restriction & & & & & & & & $\begin{array}{l}-0.051 \\
(0.144)\end{array}$ \\
\hline R-squared & 0.276 & 0.277 & 0.288 & 0.382 & 0.387 & 0.388 & 0.452 & 0.455 \\
\hline
\end{tabular}

Notes: $\mathrm{N}=40$. See Table 2 for the meaning of abbreviations for land use regulation indices. Robust standard errors are in parentheses. Estimates and standard errors for other control variables are suppressed. See Table 4 for the list of the suppressed control variables. 
by $\mathbf{s}_{\mathbf{t}}=\left(\mathbf{h}_{\mathbf{t}}, \mathbf{x}_{\mathbf{t}}\right) \in S \equiv\{0,1, \ldots, 7\}^{N} \times X$. In addition to these common state variables, chain $i$ receives two shocks, one for entry cost $v_{1 i t}$ and one for exit cost $v_{2 i t}$ at the beginning of every period. These shocks are i.i.d. draws from the Type I extremum value distribution whose mean is adjusted to be zero. Denote its CDF function by $F(\cdot)$. While the shape of the distribution function $F(\cdot)$ is common and known to all players, realized cost shocks $\boldsymbol{v}_{\mathbf{i t}}=\left(v_{1 i t}, v_{2 i t}\right)$ are private and only observable to chain $i . \beta \in(0,1)$ is a discount factor common to all chains.

\subsection{Choice Space}

At the beginning of every period, each chain simultaneously chooses the number of hotels it opens or closes. Let $a_{i t}$ denote the change in the number of hotels chain $i$ operates between period $t$ and $t+1$. Positive $a_{i t}$ indicates opening a new hotel while negative $a_{i t}$ indicates closing one of its existing hotels. I assume that entry/exit decisions made at period $t$ are realized in the next period, hence $h_{i t+1}=h_{i t}+a_{i t}$ holds. I also assume that hotel chains do not open or close more than one hotels in the same period. ${ }^{18}$ Since the resulting number of hotels after this change still has to be an element of $\{0,1, \ldots, 7\}$, chain $i$ 's choice set is a function of the number of hotels it currently operates, $h_{i t}$, and is written as

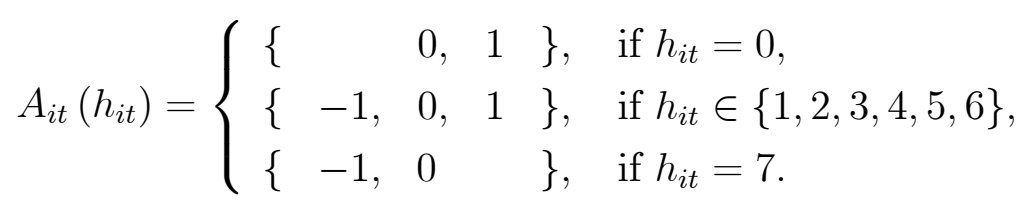

\subsection{Period Profit}

Chain $i$ 's expected period profit comes from any remaining of its expected revenue after subtracting the operating costs of its existing hotels, the sunk entry cost of opening a hotel and the exit cost of a hotel it closes.

Given the current state $\left(\mathbf{s}_{\mathbf{t}}, \boldsymbol{v}_{\mathbf{i t}}\right)$ and its entry/exit decision $a_{i t} \in A_{i t}\left(h_{i t}\right)$, chain $i$ 's choicespecific period profit is written as:

$$
\pi_{i}\left(a_{i t}, \mathbf{s}_{\mathbf{t}}, \boldsymbol{v}_{\mathbf{i t}}\right)=E R_{i}\left(\mathbf{s}_{\mathbf{t}}\right)-\delta_{i} h_{i t}-1\left(a_{i t}=1\right)\left(e_{1 i}-\rho v_{1 i t}\right)-1\left(a_{i t}=-1\right)\left(-\rho v_{2 i t}\right),
$$

where $E R_{i}\left(\mathbf{s}_{t}\right)$ represents the expected revenue of chain $i$ from its current operation of $h_{i t}$

\footnotetext{
${ }^{18}$ This assumption is not restrictive in practice since hotel chains rarely open or close more than one hotels in the same quarter. Out of 15,120 data points in my sample, only 17 data points ( 0.11 percent) experience this event. In estimation, I treat these data points as if the change were (minus) one rather than (minus) two.
} 
hotels, $\delta_{i}$ denotes the cost of operating a hotel for one period, $\left(e_{i}-\rho v_{1 i t}\right)$ is the sunk entry cost and $\left(-\rho v_{2 i t}\right)$ is the exit cost. Here the mean exit cost is assumed to be zero.

Since this period profit function is linear with respect to the structural cost parameters, I can rewrite this function as

$$
\pi_{i}\left(a_{i t}, \mathbf{s}_{\mathbf{t}}, \boldsymbol{v}_{\mathbf{i t}}\right)=\Psi\left(a_{i t}, \mathbf{s}_{\mathbf{t}}, \boldsymbol{v}_{\mathbf{i t}}\right)^{\prime} \boldsymbol{\theta}_{\mathbf{i}}
$$

where

$$
\begin{aligned}
\Psi\left(a_{i t}, \mathbf{s}_{\mathbf{t}}, \boldsymbol{v}_{\mathbf{i t}}\right) & =\left[E R_{i}\left(\mathbf{s}_{\mathbf{t}}\right),-h_{i t},-1\left(a_{i t}>0\right), 1\left(a_{i t}>0\right) v_{1 i t}, 1\left(a_{i t}<0\right) v_{2 i t}\right], \\
\boldsymbol{\theta}_{\mathbf{i}} & =\left[1, \delta_{i}, e_{1 i}, \rho, \rho\right] .
\end{aligned}
$$

\subsection{Transition of State Variables}

I assume that the evolution of market-specific characteristics $\mathbf{x}_{\mathbf{t}}$ is a Markov process. I assume that $\mathbf{x}_{\mathbf{t}}$ is exogenous. Let $P\left(\mathbf{s}^{\prime} \mid \mathbf{s}, \mathbf{a}\right): S \times S \times A \rightarrow[0,1]$ denote the evolution of the common state variables s where $A=\{-1,0,1\}^{N}$.

\subsection{Markov Perfect Equilibrium}

I assume that chain $i$ 's entry decision is characterized by a Markov strategy $\sigma_{i}\left(\mathbf{s}, \boldsymbol{v}_{\mathbf{i}}\right)$ : $S \times \mathbb{R} \rightarrow A$. When all chains follow their own Markov strategies, chain $i$ 's discounted sum of expected profits at time $t$ is

$$
\begin{aligned}
V_{i}\left(\mathbf{s}_{\mathbf{t}} ; \sigma\right) & =E_{v}\left[\sum_{\tau=t}^{\infty} \beta^{\tau-t} \Psi_{i}\left(\sigma_{i}\left(\mathbf{s}_{\boldsymbol{\tau}}, \boldsymbol{v}_{\mathbf{i} \tau}\right), \mathbf{s}_{\boldsymbol{\tau}}, \boldsymbol{v}_{\mathbf{i} \tau}\right) \boldsymbol{\theta}_{\mathbf{i}} \mid \sigma_{-i}\right] \\
& =W_{i}(\mathbf{s} ; \boldsymbol{\sigma}) \boldsymbol{\theta}_{i} .
\end{aligned}
$$

where

$$
\begin{aligned}
\sigma(\mathbf{s}, \boldsymbol{v}) & =\left\{\sigma_{1}(\mathbf{s}, \boldsymbol{v}), \ldots, \sigma_{N}(\mathbf{s}, \boldsymbol{v})\right\} \\
\sigma_{-i}(\mathbf{s}, \boldsymbol{v}) & =\sigma(\mathbf{s}, \boldsymbol{v}) \backslash\left\{\sigma_{i}(\mathbf{s}, \boldsymbol{v})\right\} \\
W_{i}(\mathbf{s} ; \sigma) & =E_{v}\left[\sum_{\tau=t}^{\infty} \beta^{\tau-t} \Psi_{i}\left(\sigma_{i}\left(\mathbf{s}_{\tau}, \boldsymbol{v}_{\mathbf{i} \tau}\right), \mathbf{s}_{\tau}, \boldsymbol{v}_{\mathbf{i} \tau}\right) \mid \sigma_{-i}\right] .
\end{aligned}
$$

In a Markov perfect equilibrium, every chain's equilibrium strategy must be the best response to its rivals' equilibrium strategy. Formally speaking, a Markov perfect equilibrium of this 
dynamic entry model consists of a vector of Markov strategy $\sigma^{*}$ such that

$$
V_{i}\left(\mathbf{s} ; \sigma_{i}^{*}, \sigma_{-i}^{*}\right) \geq V_{i}\left(\mathbf{s}, \sigma_{i}^{\prime}, \sigma_{-i}^{*}\right) \text { for all } i, \mathbf{s} \in S \text { and } \sigma_{i}^{\prime} .
$$

Exploiting the linearity of the period profit function, this equilibrium condition is rewritten as

$$
\left\{W_{i}\left(\mathbf{s} ; \sigma_{i}^{*}, \sigma_{-i}^{*}\right)-W_{i}\left(\mathbf{s} ; \sigma_{i}^{\prime}, \sigma_{-i}^{*}\right)\right\} \boldsymbol{\theta}_{i} \geq 0 \text { for all } i, s \in S \text { and } \sigma_{i}^{\prime} \text {. }
$$

\section{Estimation}

I estimate the structural parameters of the model presented in the previous section by employing the estimation method proposed by Bajari et al. (2007). Estimation consists of three stages. In the first stage, I separately estimate hotel-level revenue functions, hotel chains' reduced-form policy functions and transition functions. In the second stage, I find the set of structural cost parameters that most rationalizes the observed policy given the environment specified by the transition functions and the hotel-level revenue function. In the third stage, I infer the relationship between the recovered market-specific cost parameters and the stringency of land use regulation by running regressions.

\subsection{First Stage}

\subsubsection{Hotel-level Revenue Function}

I assume that the hotel-level revenue function of the $k$ th hotel belonging to chain $i$ at period $t$ is given by

$$
\ln r_{i k t}\left(\mathbf{s}_{t}\right)=\gamma_{i}+\eta_{1}+\mathbf{x}_{\mathbf{t}}^{\prime} \boldsymbol{\eta}_{\mathbf{2}}-\eta_{3} \ln \left(\Sigma_{j} h_{j t}\right)-\eta_{4} \ln h_{i t}+\epsilon_{i k t},
$$

where $r_{i k t}$ is a hotel-level revenue, $\gamma_{i}$ is a chain dummy, $\eta_{1}$ is a market dummy and $\epsilon_{i k t}$ is an i.i.d. draw from the normal distribution. I also include the quarter-specific dummies while I omit them from (8) for the sake of the simplicity of the equation. The fourth and fifth regressors represent the revenue impacts of the presence of other hotels in the same market. The fourth term uses the total number of midscale chain hotels in this local market while the fifth term only uses the number of hotels that belong to chain $i$. The fourth term represents the intensity of local competition in this market while the fifth term attempts to capture the possible higher substitution between hotels belonging to the same chain. I estimate this function by using OLS. 
The identification of the paramereters of (8) relies on the assumption that unobservable factors consist of the following four parts: (i) time-invariant market-specific characteristics, (ii) time-invariant chain-specific characteristics, (iii) quarter-specific shocks and (iv) unexpected idiosyncratic shocks. Time trend does not appear here since state-wide sales in $\mathbf{x}_{t}$ caputres the time trend. The dummy variables inserted in (8) deal with the first three factors while the error term $\epsilon_{i k t}$ takes care of the last one. The timing of this dynamic game does not allow unexpected idiosyncratic shocks, $\epsilon_{i k t}$ to affect $h_{i t}$.

\subsubsection{Policy Function}

I approximate hotel chains' entry/exit policies by a variant of the multinomial logit model. Let's $\Pi\left(a_{i}, \mathbf{s}\right)$ represent the deterministic part of chain $i$ 's choice-specific value function normalized by $\rho$. This function is written as

$$
\Pi_{i}\left(a_{i}, \mathbf{s}\right)=\left\{\begin{array}{lc}
\frac{1}{\rho}\left[E R_{i}(\mathbf{s})-\delta_{i} h_{i t}-1\left(a_{i t}=1\right) e_{1 i}+\beta E V_{i}\left(\mathbf{s}^{\prime} ; \sigma_{i}^{*}, \sigma_{-i}^{*} \mid \mathbf{s}, a_{i}\right)\right] & \text { if } a_{i} \in A_{i}(\mathbf{s}) \\
-\infty & \text { otherwise }
\end{array} .\right.
$$

Under this notation, I can represent chain $i$ 's decision problem as

$$
\max \left(\Pi_{i}(1, \mathbf{s})+v_{i 1}, \Pi_{i}(0, \mathbf{s}), \Pi_{i}(-1, \mathbf{s})+v_{i 2}\right) .
$$

Although the distributions of $v_{i 1}$ and $v_{i 2}$ are assumed to be the Type I extereme value distribution, the choice probability of the conventional multinomial logit model is not applicable here since hotel chains' payoff is not subject to any cost shock when they neither open nor close a hotel (i.e., $a_{i}=0$ ). Hence I derive the choice probabilities that directly captures this particular feature:

For $h_{i}=0$,

$$
\left\{\begin{array}{l}
\operatorname{Pr}\left(a_{i}=-1 \mid \mathbf{s}\right)=0 \\
\operatorname{Pr}\left(a_{i}=0 \mid \mathbf{s}\right)=\exp \left(-e^{\Pi(1, \mathbf{s})-\Pi(0, \mathbf{s})}\right) \\
\operatorname{Pr}\left(a_{i}=1 \mid \mathbf{s}\right)=1-\exp \left(-e^{\Pi(1, \mathbf{s})-\Pi(0, \mathbf{s})}\right)
\end{array}\right.
$$

For $h_{i} \in\{1,2, \cdots, 6\}$,

$$
\left\{\begin{array}{l}
\operatorname{Pr}\left(a_{i}=-1 \mid \mathbf{s}\right)=\frac{1}{1+\exp (\Pi(1, \mathbf{s})-\Pi(-1, \mathbf{s}))}\left(1-U_{i}(\mathbf{s})\right) \\
\operatorname{Pr}\left(a_{i}=0 \mid \mathbf{s}\right)=U_{i}(\mathbf{s}) \\
\operatorname{Pr}\left(a_{i}=1 \mid \mathbf{s}\right)=\frac{\exp (\Pi(1, \mathbf{s})-\Pi(-1, \mathbf{s}))}{1+\exp (\Pi(1, \mathbf{s})-\Pi(-1, \mathbf{s}))}\left(1-U_{i}(\mathbf{s})\right)
\end{array}\right.
$$


where

$$
U_{i}(\mathbf{s})=\exp \left(-e^{-\Pi(0, \mathbf{s})}\left(e^{\Pi(-1, \mathbf{s})}+e^{\Pi(1, \mathbf{s})}\right)\right) .
$$

For $h_{i}=7$,

$$
\left\{\begin{array}{l}
\operatorname{Pr}\left(a_{i}=-1 \mid \mathbf{s}\right)=1-\exp \left(-e^{\Pi(-1, \mathbf{s})-\Pi(0, \mathbf{s})}\right) \\
\operatorname{Pr}\left(a_{i}=0 \mid \mathbf{s}\right)=\exp \left(-e^{\Pi(-1, \mathbf{s})-\Pi(0, \mathbf{s})}\right) \\
\operatorname{Pr}\left(a_{i}=1 \mid \mathbf{s}\right)=0
\end{array}\right.
$$

Appendix A shows the derivation of these formulas. I estimate the parameters of each hotel chains' policy function by approximating $\Pi(1, \mathbf{s})-\Pi(-1, \mathbf{s})$ and $\Pi(0, \mathbf{s})-\Pi(-1, \mathbf{s})$ as a linear function of state variables including market fixed effects. I use the maximum likelihood for this estimation.

\subsection{Transition Function}

I include the following three variables: (i) population, (ii) the number of establishments and (iii) state-level sales of midscale hotels into x. I estimate their transition functions by running AR1 regressions.

\subsection{Second Stage}

In the second stage, I find the set of chain $i$ 's structural cost parameters $\left\{\delta_{i}, e_{i}\right\}$ of each local market that make the observed policy the most profitable choice compared to possible alternatives.

\subsubsection{Forward Simulations}

I first generate many alternative policies that slightly deviate from chain $i$ 's observed policy. Next, by forward simulation, I approximate chain $i$ 's discounted sum of expected profits in the following two situations: (1) when all chains follow the observed policy; and (2) when chain $i$ follows one of the alternative policies while its rival chains follow the observed ones. To be specific, I follow the steps below to implement this idea:

1. Fix a market and a hotel chain $i$.

2. Generate chain $i$ 's $N_{I}$ alternative policies by slightly perturbing the observed policy 
function obtained in the first stage. ${ }^{19}$ Let $\left\{\sigma_{i}^{k}\right\}_{k=1}^{N_{I}}$ denote a set of such alternative policies for chain $i$. For notational convenience, let $\sigma_{i}^{0}$ denote chain $i$ 's observed policy.

3. Let $n$ denote the index of the forward simulation. At the beginning of $n$th simulation, generate a simulated series of $\mathbf{x}_{t}$ for $T$ periods by using the AR1 models obtained in the first stage. Denote this series as $\left\{\tilde{\mathbf{x}}_{\tau}^{n}\right\}_{\tau=0}^{T}$. For $\tilde{\mathbf{x}}_{0}^{n}$, use the corresponding value in the raw data at the initial sample period.

4. Simulate the entry decisions of all hotel chains for $T$ periods when (i) all chains including chain $i$ follow the observed policy $\sigma^{0}$ and (ii) chain $i$ follows the $k$ th alterantive policy $\sigma_{i}^{k}$ while its rivals follow the observed policy $\sigma_{-i}^{0}$.

(a) Calculate chain $i$ 's revenue, $\tilde{R}_{i t}^{k, n}$, by using the first stage estimates and a vector of simulated state variables $\tilde{\mathbf{s}}_{t}^{n}=\left(\tilde{\mathbf{h}}_{t}^{n}, \tilde{\mathbf{x}}_{t}^{n}\right)$. For $\tilde{\mathbf{h}}_{0}^{n}$, use the corresponding value in the raw data at the initial period.

(b) For each chain, generate two i.i.d. random draws from the Type I extereme value distribution and simulate its entry/exit decision, $\tilde{a}_{i t}^{k, n}$ based on its corresponding policy.

(c) Iterate this process for every alternative policy, $k \in\left\{0,1 \ldots, N_{I}\right\}$. Note that chain $i$ follows the observed policy when $k=0$.

(d) Iterate Step 3 and 4 for $N_{S}$ times and for every alternative policy $k \in\left\{0,1 \ldots, N_{I}\right\}$, calculate

$$
\tilde{W}_{i}\left(\sigma_{i}^{m}, \sigma_{-i}^{0}\right)=\frac{1}{N_{S}} \sum_{n=1}^{N_{S}} \sum_{t=0}^{T} \beta^{t}\left[\begin{array}{l}
\tilde{R}_{i t}^{k, n},-\tilde{h}_{i t}^{k, n},-1\left(\tilde{a}_{i t}^{k, n}=1\right), 1\left(\tilde{a}_{i t}^{k, n}=1\right) v_{1 i t}, \\
-1\left(\tilde{a}_{i t}^{k, n}=-1\right), 1\left(\tilde{a}_{i t}^{k, n}=-1\right) v_{2 i t}
\end{array}\right] .
$$

In the actual estimation, I employ the following setting: $N_{I}=800, N_{S}=10,000, T=80$ and $\beta=.974$. Note that the unit of the time period is quarter rather than year. Hence $T=80$ is equivalent to 20 years and $\beta=.974$ is equivalent to .9 annual discount rate

\subsubsection{Recovering Cost Parameters}

Based on the outcome of the forward simulations, I evaluate chain $i$ 's relative profitability of choosing the observed policy $\sigma_{i}^{0}$ compared to the set of the alternative policies $\left\{\sigma_{i}^{k}\right\}_{k=1}^{N_{I}}$

\footnotetext{
${ }^{19}$ I implement this idea as follows. I first generate $N_{I}$ vectors, $\left(\gamma^{1}, \cdots, \gamma^{N_{I}}\right)$ of i.i.d. random draws from the standard normal. The length of $\gamma^{k}$ is equal to that of $\lambda_{i}$. Second, pertubate the estimates of the observed policy function by using $\lambda_{i}^{k}$ as its parameters instead of estimated $\lambda_{i}$, where $\lambda_{i}^{k}=\left(1+.005 \gamma_{i}^{k}\right) \lambda_{i}$.
} 
for a given set of parameters $\theta$, based on the following loss function:

$$
\begin{aligned}
& \frac{1}{N_{I}} \sum_{k=1}^{N_{I}}\left(\min \left\{g_{k i}(\boldsymbol{\theta}), 0\right\}\right)^{2} \\
& \text { where } g_{k i}(\boldsymbol{\theta})=\left\{\tilde{W}_{i}\left(\sigma_{i}^{0}, \sigma_{-i}^{0}\right)-\tilde{W}_{i}\left(\sigma_{i}^{k}, \sigma_{-i}^{0}\right)\right\} \boldsymbol{\theta} .
\end{aligned}
$$

This loss function calculates to what extent an alternative policy brings more profit to chain $i$ than the observed policy when its rivals follow their own observed policies. If the observed policy $\sigma_{i}^{0}$ brings more profit than an alternative one $\sigma_{i}^{k}$ for a given $\boldsymbol{\theta}$, this function gives zero. In contrast, when the opposite is true, we have $\left(\min \left\{g_{k i}(\boldsymbol{\theta}), 0\right\}\right)^{2}=\left(g_{k i}(\boldsymbol{\theta})\right)^{2}$.

Finally I estimate structural cost parameter $\boldsymbol{\theta}^{*}$ by finding the one that minimizes this loss function subject to nonnegative constraints. Since I assume $\rho$ is common for all players in all markets, I need to add up the above loss function across both chains and markets

$$
\left(\rho^{*}, \boldsymbol{\delta}^{*}, \mathbf{e}^{*}\right)=\arg \min _{(\rho, \boldsymbol{\delta}, \mathbf{e}) \in R_{+}} \frac{1}{6 \cdot 40 \cdot N_{I}} \sum_{m=1}^{40} \sum_{i=1}^{6} \sum_{k=1}^{N_{I}}\left(\min \left\{g_{m k i}(\boldsymbol{\theta}), 0\right\}\right)^{2} .
$$

where $\boldsymbol{\delta}$ and $\mathbf{e}$ are $N_{m} \times 6$ matrices of operating costs and sunk entry cost, respectively. I add a subscript $m$ to $g(\cdot)$ to emphasize that this function is market-chain-policy specific. One thing worth mentioning here is that the linearity of the period profit function significantly reduces the computational burden of the estimation of this model. Without this linearity assumption, I would have to conduct forward simulations to evaluate the loss function for each possible $\boldsymbol{\theta}$, making estimation practically infeasible.

\subsection{Third Stage}

The last step aims to infer the impacts of the stringency of land use regulation on marketspecific structural cost parameters $\left(\delta_{m}, e_{m}\right)$. I assume that the logarithm of these marketspecific costs are linear functions of land use regulation indices, hotel chain dummy and other observable market-specific cost factors. 
Table 7: Policy Function Estimates

\begin{tabular}{lrrrr}
\hline \hline & \multicolumn{3}{c}{$(1)$} & \multicolumn{2}{c}{$(2)$} \\
\cline { 2 - 5 } & \multicolumn{1}{c}{$\lambda^{0}$} & $\lambda^{1}$ & $\lambda^{0}$ & \multicolumn{1}{c}{$\lambda^{1}$} \\
\hline \multirow{3}{*}{ \# of Hotels } & 0.007 & 0.022 & -0.061 & -0.178 \\
\# of Hotels under the Same Chain & $(0.036)$ & $(0.041)$ & $(0.052)$ & $(0.062)$ \\
& -0.714 & -0.998 & -0.787 & -1.060 \\
Population & $(0.089)$ & $(0.110)$ & $(0.105)$ & $(0.123)$ \\
\multirow{2}{*}{ Establishments } & -0.061 & -0.025 & -4.016 & -0.347 \\
Sales & $(0.363)$ & $(0.430)$ & $(2.625)$ & $(3.108)$ \\
& 0.369 & 1.044 & 4.887 & 3.384 \\
& $(0.417)$ & $(0.491)$ & $(2.158)$ & $(2.534)$ \\
Log Likelihood & 0.488 & 1.566 & 0.827 & 2.647 \\
Market Dummy & $(0.406)$ & $(0.482)$ & $(0.525)$ & $(0.638)$ \\
& & & & -2280.50 \\
& -2324.542 & & \\
\end{tabular}

Notes: N=15,120. Standard erros are in parentheses. Population, establishments and sales are in log. Estimates and standard errors for market dummies, chain dummies and thresholds are suppressed. Likelihood fucnctions explicitly take into account the constraint that no closure is possible when hotel chains operate no hotels.

\section{Results}

\subsection{First Stage}

\subsubsection{Policy Function}

Table 7 shows the estimation results of the policy function specified in 6.1.2. To see the empirical importance of unobservable market-specific characteristics, I estimate this function under two different specifications: one with market dummy variables and one without them. First, the estimation results indicate that hotel chains are less likely to open additional hotels in markets where they have already operated some. Second, including market dummy variables into regressors are crucial to properly characterize the policy functions. As shown in Table 7, these two specifications provide quite different conclusions on the extent to which the presence of incumbents affect hotel chains' entry decisions. These results suggest 

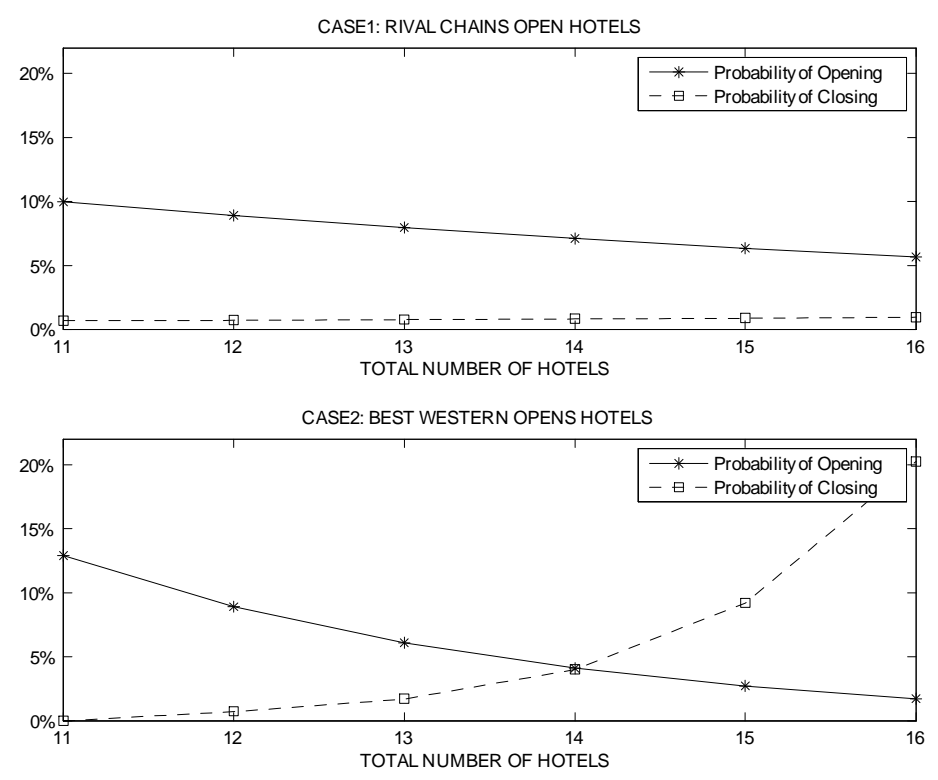

Figure 3: IMPACTS OF THE NUMBER OF INCUMBENTS ON BEST WESTERN'S ENTRY DECISIONS

that observable characteristics (i.e., population and establishments) are not sufficient to characterize the demand size of local markets. Hereafter I use the estimation results of the model using market dummy variables.

To provide some idea about what these estimates imply, I calcluate the change in Best Western's predicted entry (i.e., $a_{i t}=1$ ) and exit (i.e., $a_{i t}=-1$ ) probabilities in a market ${ }^{20}$ as the number of hotels in this market increases. I consider the following two cases. In case one, the number of hotels belonging to other hotel chains increase from ten to fifteen while Best Western operates only one hotel. In case two, the number of hotels operated by Best Western increases from zero to five while the number of hotels operated by the other chains are fixed at eleven. In both cases, the total number of hotels increase from eleven to sixteen. Figure 3 shows the result of this exercise. In case one, Best Western's entry probability decreases from about ten percent to six percent as rival chains open new hotels while its exit probability slightly increases from 0.7 percent to one percent. In contrast, refelcting high substitution between hotels under the same chain, its entry probability decreases from 13 percent to 1.7 percent and its exit probability increases from 0 percent to 20 percent.

\footnotetext{
${ }^{20}$ This figure uses the data of Potter county, a part of the Amarillo MSA, in the first quarter of 2005. The population of this market is close to the sample median in this period.
} 


\subsubsection{Revenue Function}

Table 8 shows estimation results of the revenue function specified in eq (8). I use the OLS for this estimation. To take into account possible correlations between error terms of hotels that operate in the same market at the same time, I employ the standard errors robust to clustering. I estimate this function under two specifications, with and without using market dummy variables to see the empirical relevance of imposing market-specific dummy variables.

First, my estimation results shows that imposing market-specific dummy variables significantly changes some of my parameter estimates. In particular, the parameter estimate for the number of rival hotels (the first row) changes from -.047 to -.380. These results imply that ignoring market-specific unobservable factors lead to inconsistent parameter estimates. For further analysis, I use the parameter estimates based on the specification using market dummy variables. Second, my estimation results indicate that the presence of rival hotels significantly reduces the revenue of a hotel. In particular, its revenue impact becomes more severe when the hotel and its rival hotels belong to the same chain. Figure 4 visibly illustrates the implication of these results by showing how the revenue of a hotel decreases as it faces more rival hotels. To highlight the distinct revenue impacts from hotels belonging to the same chain and those belonging to its rival chains, the figure considers two situations: (1) when all of its rival hotels belong to hotel chains and (2) when the hotel and all of its rival hotels belong to the same chain. My estimation results imply that when a hotel competes with one hotel (i.e., duopoly), its revenue is about 23 percent lower than its revenue under the monopoly when its rival hotel belongs to different chains. However, when its rival hotel belongs to the same chain, its revenue decreases by 34 percent. $^{21}$

\subsubsection{Transition Function}

Table 9 reports estimation results of the transition functions for state-level sales, marketlevel establishments and population. Quarterly data are available for state sales while it is not the case for the other two. Estimates of quarterly dummy variables verify that strong seasonal demand in summer (second quarter) and weak seasonal demand in winter (fourth quarter).

\footnotetext{
${ }^{21}$ Some might wonder why more intense competition due to the change from monopoly to duopoly does not decrease the revenue of a hotel more than 50 percent. This conjecture is not necessarily true in my setting that abstracts hotel chains' within-market location decisions. The location of the second hotel is generally different from that of the first one and as a result the first hotel needs to compete with the second hotel for only a fraction of its potential customers.
} 
Table 8: Revenue Function Estimates

\begin{tabular}{lcc}
\hline \hline & $(1)$ & $(2)$ \\
\hline \multirow{3}{*}{ \# of Hotels } & -0.047 & -0.380 \\
& $(0.023)$ & $(0.025)$ \\
\# of Hotels under the Same Chain & -0.198 & -0.230 \\
& $(0.019)$ & $(0.018)$ \\
Population & -0.539 & -0.106 \\
& $(0.045)$ & $(0.159)$ \\
Establishments & 0.844 & 0.324 \\
Sales & $(0.046)$ & $(0.132)$ \\
& -0.141 & 0.362 \\
Market Dummy & $(0.040)$ & $(0.036)$ \\
R-squared & & \\
& No & Yes \\
& & \\
\hline
\end{tabular}

Notes: N=15,482. Cluster standard erros are in parentheses. Each cluster is market and time period specific. Population, establishments and sales are in log. Estimates and standard errors for market dummies, chain dummies and quarter dummies are suppressed.
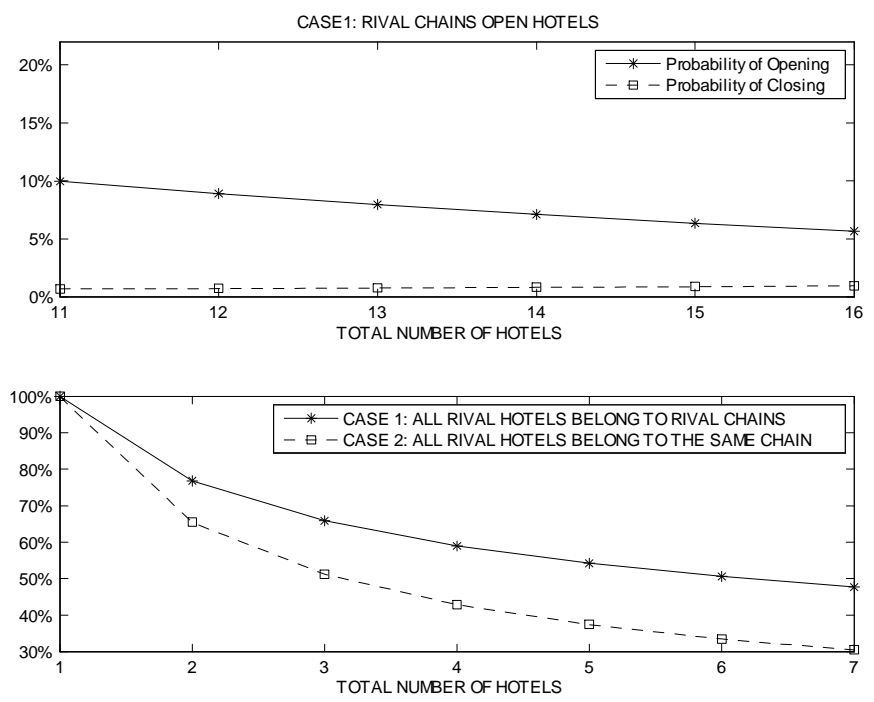

Figure 4: Revenue Impacts of Having Rival Hotels 
Table 9: Transition Function Estimates

\begin{tabular}{cccc}
\hline \hline & \multicolumn{3}{c}{ Dependent Variables } \\
\cline { 2 - 4 } Lagged Dep. Var. & 0.992 & 1.005 & 1.002 \\
& $(0.020)$ & $(0.001)$ & $(0.002)$ \\
Constant & $\cdot$ & 0.013 & 0.022 \\
& $\cdot$ & $(0.001)$ & $(0.005)$ \\
Quarter Dummy & & & \\
Q1 & 0.076 & & \\
Q2 & $(0.114)$ & & \\
Q3 & 0.170 & & \\
Q4 & $(0.114)$ & & \\
& 0.045 & & \\
& $(0.117)$ & & \\
\hline
\end{tabular}

Notes: $\mathrm{N}=64$ for sales and 1,020 for establishments and population. Standard erros are in parentheses. All dependent variables are in log.

\subsection{Second Stage}

The second stage estimation provides the common variance parameter $\rho^{*}$ and a pair of operatioon cost and sunk-entry cost $\left(\delta_{m i}, e_{m i}\right)$ for each combination of market-chain. I describe these estimates from two different angles: its market average and its chain-specific average.

Table 10 reports descriptive statistics for the distribution of market average cost, $\left(\delta_{m i}, e_{m i}\right)$. In a hypothetical market whose cost parameters are equal to the sample average, a hotel chain incurs $\$ 233$ thousand for every quarter to operate a hotel and incur about $\$ 3.7$ milliion to open a new hotel. My estimates also indicate that the values of cost parameters significantly vary across markets. Operation cost of the market at the third quartile is about three times higher than that of the market at the first quartile. In contrast, sunk cost of the market at the third quartile is about 40 percent higher than that of the market at the first quartile.

Table 11 reports the chain-specific average of cost parameter estimates, $\left(\delta_{m i}, e_{m i}\right)$ and the median of the number of rooms. These results clearly indicate that the cost structure of each hotel chain is significantly different. For example, the operation cost Inter-Continental incurs is more than twice as much as that of Best Western. Capacity difference explains a part of this difference. The median number of rooms of a hotel is eighty for Inter-Continental 
Table 10: Summary Statistics of the Market-Average Cost Parameter Estimates

\begin{tabular}{lrr}
\hline \hline & $\begin{array}{l}\text { Operating } \\
\text { Cost }(\delta)\end{array}$ & $\begin{array}{l}\text { Sunk Entry } \\
\text { Cost }(e)\end{array}$ \\
\hline & & \\
Mean & 232.5 & 3714.0 \\
Std. Dev. & 153.6 & 1030.2 \\
P25 & 104.8 & 3163.2 \\
P50 & 189.6 & 3926.0 \\
P75 & 327.2 & 4464.0 \\
& & \\
\hline
\end{tabular}

Notes: $\mathrm{N}=40$. All statistics are in thousand dollars.

Table 11: Average Cost Parameter Estimates: By Chain

\begin{tabular}{lrrr}
\hline \hline & $\begin{array}{c}\text { Operating } \\
\text { Cost }(\delta)\end{array}$ & $\begin{array}{l}\text { Sunk Entry } \\
\text { Cost }(e)\end{array}$ & $\begin{array}{c}\text { Median Number } \\
\text { of Rooms }\end{array}$ \\
\hline Best Western & & & \\
Cendant & 163.8 & $3,709.3$ & 61 \\
Choice Hotels & 114.3 & $3,973.7$ & 85 \\
Hilton & 114.0 & $3,839.9$ & 60 \\
Inter-Continental & 223.3 & $4,274.4$ & 69 \\
La Quinta & 385.5 & $3,505.4$ & 80 \\
& 416.1 & $2,909.7$ & 114 \\
\hline
\end{tabular}

Notes: Operating cost and sunk entry cost are in thousand dollars. Operating cost expresses the amount of cost a hotel incurs for its three-month operation.

while the corresponding number is sixty-one for Best Western. The difference not explained by this capacity difference may reflect possible quality difference between chains such as the availability of free breakfast or business centers.

I next examine the relevance of these estimates by comparing them with cost data provided by industrial source. In particular, I look at the estimate for Best Western and La Quinta since their company websites provide detailed information about their construction guidelines. According to my calculation, construction cost of a new Best Western hotel is about $\$ 3.4$ million while my point estimate for its sunk entry cost is $\$ 3.7$ million. For La Quinta, its construction cost is $\$ 4.5$ million while my point estimate is $\$ 2.9$ million. See an appendix for the details of how I calculate these numbers. 


\subsection{Third Stage: Cost Function Regression}

Table 12 and Table 13 report regression estimates for operation cost function $\left(\delta_{m j}\right)$ and sunk entry cost function $\left(e_{m j}\right)$ under various specifications, respectively. ${ }^{22}$ To avoid omitted variable problems, all the regressions here include the control variables used in the reduced form regressions. The regression results indicate that the stringency of land use regulation increases both operation cost and sunk-entry cost. The last column of Table 12 shows that five out of the seven parameter estimates of land use regulation indices on operation cost are statistically signifincat at least ten percent significant level. The signs of Political Pressure and Open Space are all consistent with my hypothesis while other three (Density Restriction, Exactions and Approval Delay) are not. However, the quantitative impacts of the first group are much larger than those of the second group. These point estimates indicate that the change in the five indices that statistically significant from the first quartile to the third quartile increases the operation cost by 5.4 percent. The impact goes up to 12.1 percent if I include all seven indices regardless of their statistical significance. As for sunk entry cost, the last column of Table 13 shows that the estimate for Project Approval index is statistically signiciant and its sign is consistent with my hypothesis. These estimates indicate that the change in this index from the first quartile to the third quartile increases the sunk entry cost by 20 percent. The impact goes up to 23 percent if I change the value of all the seven indices regardless of their statistical significance.

One limitation of these estimates are possible simultaneity between market-specific costs and the stringency of land use regulation. When local governments determine the stringency of regulation by looking at local business costs, these regression estimates are possibly inconsistent. The standard solution of this problem is to find valid instruments that exogenously shift the stringency of land use regulation. However, it is little hope to find such valid instruments, ${ }^{23}$ let alone the fact that I have to find seven different such instruments.

\section{Counterfactual Experiments}

This section shows the results of policy experiments, using the parameter estimates obtained in the previous section. The goal of this exercise is to quantitatively evaluate the supply side

\footnotetext{
${ }^{22}$ I exclude the three chain-market combinations from the regression for sunk entry cost function since I get zero as estimates. Excluding these three combinations from the operation cost function barely change the estimates.

${ }^{23}$ McMillen and McDonald (1991a) and McMillen and McDonald (1991b) examine the possible selection bias in land value function estimation when zoning decisions are endogenous. For instruments, they use an indicator variable that tells whether a parcel is incorporated or not by municipals. This instrument is not applicable in my study since my study focuses on the effects of land use regulation on a county as a whole rather than each single parcel within a county.
} 
Table 12: OLS Estimates of Regulation Impacts on Operation Cost

\begin{tabular}{|c|c|c|c|c|c|c|c|}
\hline & \multicolumn{7}{|c|}{ Dep. Var. = Log of Operation Cost } \\
\hline & (1) & $(2)$ & $(3)$ & $(4)$ & $(5)$ & $(6)$ & (7) \\
\hline Political Pressure & $\begin{array}{c}0.129 \\
(0.024)\end{array}$ & $\begin{array}{c}0.128 \\
(0.024)\end{array}$ & $\begin{array}{c}0.125 \\
(0.023)\end{array}$ & $\begin{array}{c}0.124 \\
(0.025)\end{array}$ & $\begin{array}{c}0.123 \\
(0.025)\end{array}$ & $\begin{array}{c}0.111 \\
(0.026)\end{array}$ & $\begin{array}{r}0.079 \\
(0.026)\end{array}$ \\
\hline Density Rest. & & $\begin{array}{c}-0.118 \\
(0.078)\end{array}$ & $\begin{array}{l}-0.237 \\
(0.095)\end{array}$ & $\begin{array}{l}-0.235 \\
(0.103)\end{array}$ & $\begin{array}{l}-0.257 \\
(0.104)\end{array}$ & $\begin{array}{l}-0.251 \\
(0.101)\end{array}$ & $\begin{array}{c}-0.249 \\
(0.096)\end{array}$ \\
\hline Exactions & & & $\begin{array}{c}-0.359 \\
(0.109)\end{array}$ & $\begin{array}{l}-0.356 \\
(0.114)\end{array}$ & $\begin{array}{l}-0.383 \\
(0.118)\end{array}$ & $\begin{array}{l}-0.344 \\
(0.112)\end{array}$ & $\begin{array}{c}-0.404 \\
(0.119)\end{array}$ \\
\hline Aprvl Delay & & & & $\begin{array}{l}-0.004 \\
(0.022)\end{array}$ & $\begin{array}{l}-0.022 \\
(0.019)\end{array}$ & $\begin{array}{l}-0.034 \\
(0.020)\end{array}$ & $\begin{array}{c}-0.042 \\
(0.020)\end{array}$ \\
\hline Zoning Aprvl & & & & & $\begin{array}{l}-0.078 \\
(0.041)\end{array}$ & $\begin{array}{l}-0.054 \\
(0.041)\end{array}$ & $\begin{array}{c}-0.062 \\
(0.042)\end{array}$ \\
\hline Project Aprvl & & & & & & $\begin{array}{c}0.080 \\
(0.050)\end{array}$ & $\begin{array}{c}0.075 \\
(0.049)\end{array}$ \\
\hline Open Space & & & & & & & $\begin{array}{c}0.199 \\
(0.073)\end{array}$ \\
\hline R-squared & 0.780 & 0.790 & 0.800 & 0.800 & 0.800 & 0.800 & 0.810 \\
\hline
\end{tabular}

Notes: $\mathrm{N}=234$. Robust standard errors are in parentheses. Population and area are in $\log$. 
Table 13: OLS Estimates of Regulation Impacts on the Distribution of Sunk Entry Cost

\begin{tabular}{|c|c|c|c|c|c|c|c|}
\hline & \multicolumn{7}{|c|}{ "Dep. Var. = Log of Sunk Entry Cost } \\
\hline & $(1)$ & $(2)$ & $(3)$ & $(4)$ & $(5)$ & $(6)$ & $(7)$ \\
\hline \multirow[t]{2}{*}{ Political Pressure } & 0.022 & 0.023 & 0.022 & 0.022 & 0.022 & -0.001 & -0.011 \\
\hline & $(0.030)$ & $(0.031)$ & $(0.030)$ & $(0.032)$ & $(0.032)$ & $(0.032)$ & $(0.032)$ \\
\hline \multirow[t]{2}{*}{ Density Rest. } & & 0.069 & 0.037 & 0.038 & 0.038 & 0.050 & 0.050 \\
\hline & & $(0.069)$ & $(0.074)$ & $(0.074)$ & $(0.078)$ & $(0.079)$ & $(0.080)$ \\
\hline \multirow[t]{2}{*}{ Exactions } & & & -0.097 & -0.096 & -0.095 & -0.019 & -0.038 \\
\hline & & & $(0.113)$ & $(0.114)$ & $(0.121)$ & $(0.124)$ & $(0.124)$ \\
\hline \multirow[t]{2}{*}{ Aprvl Delay } & & & & -0.002 & -0.002 & -0.025 & -0.028 \\
\hline & & & & $(0.017)$ & $(0.021)$ & $(0.020)$ & $(0.020)$ \\
\hline \multirow[t]{2}{*}{ Zoning Aprvl } & & & & & 0.002 & 0.048 & 0.046 \\
\hline & & & & & $(0.051)$ & $(0.057)$ & $(0.057)$ \\
\hline \multirow[t]{2}{*}{ Project Aprvl } & & & & & & 0.151 & 0.149 \\
\hline & & & & & & $(0.069)$ & $(0.070)$ \\
\hline Open Space & & & & & & & 0.061 \\
\hline & & & & & & & $(0.100)$ \\
\hline R-squared & 0.190 & 0.190 & 0.190 & 0.190 & 0.190 & 0.220 & 0.220 \\
\hline
\end{tabular}

Notes: $\mathrm{N}=237$. Robust standard errors are in parentheses. 


\section{Table 14: Summary Statistics of the Sample Markets}

\begin{tabular}{lr}
\hline \hline & Grayson County \\
\hline & \\
Population (in thousand) & 116.8 \\
Area (in sq mi) & 933.5 \\
\# of Establishments (in thousand) & 2.6 \\
Employments (in thousand) & 36.6 \\
MSA Dummy & 1.0 \\
Airport Dummy & 0.0 \\
Interstate Highway Dummy & 0.0 \\
\end{tabular}

Notes: As of the first quarter of 2005.

effect of regulation change on entry decisions of hotel chains and the change in the intensity of competition. To isolate this particular effect, I construct an imaginary environment where land use regulation affects only cost but not demand.

\subsection{Environments}

My counterfactual experiments consider Grayson County in which two hotel chains (Best Western and Cendant) consider their entry decisions every period. In 2005, the population of this market is equal to the sample median. Table 14 shows the basic information of this market. Ideal experiments might be the ones that allow all seven heterogeneous hotel chains to make entry decisions in each of forty markets considered in the previous chapter. However, the limitation of computational resources prevents this approach. For that reason, the results of counterfactual experiments shown here should be considered as a mean that helps us understand what the structural estimates convey rather than the predicted market structure under hypothetical policies in these local markets. I simulate the entry-exit decisions of these two hotel chains under three different policies: Q1, Q2 and Q3. Each policy is different in terms of the value of land use regulation indices. Under Q1, the value of all land use regulation indices are set to be equal to the sample first quartile. Land use regulation indices under Q2 and Q3 are also constructed in the same way. 


\subsection{Procedure}

I first calculate the operation costs and the sunk entry costs of these two chains under each policy by using the OLS estimates in the last column of Table 12 and Table $13 .{ }^{24}$ I next numerically solve the Bellman equation under a particular set of structural parameters to obtain the approximated value function and the resulting policy functions. Using these equilibrium policy functions, I simulate the model. I employ the algorithm originally suggested by Pakes and McGuire (1994) and extended by Doraszelski and Satterthwaite (forthcoming) to games of incomplete information. In all the experiments, I fix all market-specific values such as population to their value in the first quarter of 2005 to reduce the state space. Hence the state space consists of the number of hotels belonging to one's chain, the number of hotels belonging to the rival chain and which quarter the current period is. The number of possible states is 256. All the experiments converge after around 600 iterations.

\subsection{Simulation Results}

Table 15 reports the results of the counterfactual experiments. All variables except producer surplus are based on the sample average of the simulated periods while the producer surplus comes from the value of the value function under the initial state. ${ }^{25}$ The simulation results support the empirical relevance of my hypothesis that stringent regulation leads to fewer entries. Under the most lenient policy $(Q 1)$, the average number of hotels in the small market is 2.2. As the policy becomes more stringent, this number decreases to $2.0(Q 2)$ and 1.6 (Q3). Assuming the number of rooms of each hotel is equal to the chain-average, these results imply that imposing stringent regulation increases the revenue per room by three percent $(Q 1 \rightarrow Q 2)$ and twelve percent $(Q 1 \rightarrow Q 3)$ regardless of chains. These increases are suggestive of higher prices in the market imposing more stringent regulation. Despite of higher market power, hotel chains do not necessarily make more profits. According to the results, the change from the most lenient policy $(Q 1)$ to the modest one $(Q 2)$ decreases the producer surplus by $\$ 1.5$ million while the change to the most stringent one $(Q 3)$ decreases it by $\$ 6.4$ million, respectively.

\footnotetext{
${ }^{24}$ All point estimates are used regardless of their statistical significance.

${ }^{25}$ Calculating consumer surplus is not possible in this model since the model abstracts the demand side by using the revenue function.
} 
Table 15: Counterfactual Experiments

\begin{tabular}{lrrr}
\hline \hline & & & \\
& & & \\
& & & \\
& Q1 & Q2 & Q3 3 \\
\cline { 2 - 4 } & & & \\
& & & \\
Operation Costs (in thousand dollars) & 91.76 & 98.70 & 102.89 \\
Best Western & 75.67 & 81.39 & 84.84 \\
Cendant & & & \\
& & & \\
Sunk Entry Costs (in thousand dollars) & & & \\
Best Western & $4,454.3$ & $4,711.8$ & $5,592.4$ \\
Cendant & $3,831.4$ & $3,963.9$ & $4,704.7$ \\
& & & \\
\# of Hotels & & & \\
Total & 2.22 & 2.04 & 1.61 \\
Best Western & 1.05 & 1.09 & .75 \\
Cendant & 1.17 & .95 & .86 \\
& & & \\
Daily Revenue per Room (in dollars) & & & \\
Best Western & 28.55 & 29.48 & 31.94 \\
Cendant & 14.77 & 15.26 & 16.55 \\
& & & \\
Producer Surplus (in million dollars) & 14.15 & 12.66 & 7.76 \\
Best Western & 5.95 & 5.26 & 3.13 \\
Cendant & 8.20 & 7.39 & 4.63 \\
& & & \\
\hline
\end{tabular}

Notes: Daily revenue per room is obtained by dividing quarter revenue by ninetytwo days. 


\section{Conclusion}

This paper studies the role of land use regulation as a barrier to entry in the case of the midscale Texas lodging industry. I argue that stringent land use regulation lessens local competition by increasing the costs of hotels. This lessened competition generates a distortion by providing hotels that enter with additional market power. The structural estimates obtained in this paper are informative to assess the empirical relevance of this hypothesis. According to my estimates, the change in the stringency of land use regulation from the sample first quartile level to the sample third quartile level increases the level of the marketspecific operating cost by 5.4 percent and that of sunk-entry cost by 24 percent, respectively. As a result, the revenue-per-room, a proxy for the price, increases by 12 percent.

This paper is among the first to empirically examine the anticompetitive effect of land use regulation on local business markets. Although people in the lodging business and legal professions have noticed it, there has been no formal analysis that quantifies this effect. This paper also contributes an introduction of structural estimation to the literature. Although reduced form estimates might be more flexible from restrictive assumptions, they do not tell whether these results come through the supply side or the demand side. The structural estimation employed in this paper has the advantage of separately identifying these two effects.

\section{References}

Bajari, P., C. L. Benkard, and J. Levin (2007). Estimating dynamic models of imperfect competition. Econometrica 75(5), 1331-1370.

Berry, S. T. (1992). Estimation of a model of entry in the airline industry. Econometrica $60(4), 889-917$.

Berry, S. T. and P. C. Reiss (2007). Empirical Models of Entry and Market Structure, pp. 1845-1886. Handbook of Industrial Organization Volume 3. Amsterdam: Elsevier B.V.

Bresnahan, T. F. and P. C. Reiss (1990). Entry in monopoly markets. Review of Economic Studies 57(4), 531-553.

Cheshire, P. and S. Sheppard (2004). Land markets and land market regulation: Progress towards understanding. Regional Science and Urban Economics 34(6), 619-637.

Chung, W. and A. Kalnins (2001). Agglomeration effects and performance: A test of the Texas lodging industry. Strategic Management Journal 22(10), 969-988. 
Conlin, M. and V. Kadiyali (2006). Entry-deterring capacity in the Texas lodging industry. Journal of Economics $\mathcal{E}$ Management Strategy 15(1), 167-185.

Cruz, T. D. (2003, 08/01). Developers overcome obstacles for desirable projects. Hotel $\&$ Motel Management 218(14), 26.

Doraszelski, U. and M. Satterthwaite (forthcoming). Computable markov-perfect industry dynamics: Existence, purification, and multiplicity. RAND Journal of Economics.

Evans, A. W. (1999). The Land Market And Government Intervention, pp. 1637-1669. Handbook of Regional and Urban Economics. Amsterdam: Elsevier Science B. V.

Fischel, W. A. (1985). The economics of zoning laws: A property rights approach to American land use controls. Baltimore: John Hopkins University Press.

Fischel, W. A. (1989). Do growth controls matter?: A review of empirical evidence on the effectiveness and efficiency of local government land use regulation. Cambridge, Mass.: Lincoln Institute of Land Policy.

Glaeser, E. L., J. Gyourko, and R. Saks (2005a). Why is Manhattan so expensive?: Regulation and the rise in housing prices. Journal of Law and Economics XLXIII, 331-369.

Glaeser, E. L., J. Gyourko, and R. E. Saks (2005b). Why have housing prices gone up? American Economic Review 95(2), 329-333.

Glaeser, E. L. and B. A. Ward $(2009,5)$. The causes and consequences of land use regulation: Evidence from greater boston. Journal of Urban Economics 65(3), 265-278.

Gyourko, J., A. Saiz, and A. A. Summers (2008). A new measure of the local regulatory environment for housing markets: The Wharton Residential Land Use Regulatory Index. Urban Studies 45, 693-729.

Kalnins, A. (2004). An empirical analysis of territorial encroachment within franchised and company-owned branded chains. Marketing Science 23(4), 476-489.

Kunce, M., S. Gerking, and W. Morgan $(2002,12)$. Effects of environmental and land use regulation in the oil and gas industry using the Wyoming checkerboard as an experimental design. American Economic Review 92(5), 1588-1593.

Mazzeo, M. J. (2002). Product choice and oligopoly market structure. RAND Journal of Economics 33(2), 221-242.

McConnell, V., M. Walls, and E. Kopits $(2006,5)$. Zoning, TDRs and the density of development. Journal of Urban Economics 59(3), 440-457.

McMillen, D. and J. McDonald (1991a). A simultaneous equations model of zoning and land values. Regional Science and Urban Economics 21(1), 55-72. 
McMillen, D. and J. McDonald (1991b). Urban land value functions with endogenous zoning. Journal of Urban Economics 29(1), 14-27.

Nance, C. P. (2006). Modern real estate practice in Texas. Chicago, IL: Dearborn Real Estate Education.

Nishida, M. (2010). Estimating a model of strategic network choice: The convenience-store industry in Okinawa. Johns Hopkins University Working Paper.

OECD (2008). Land use restrictions as barriers to entry.

O'Flaherty, B. (2005). City economics. Cambridge, Mass.: Harvard University Press.

O'Sullivan, A. (2000). Urban economics. Boston: McGraw-Hill/Irwin.

Pakes, A. and P. McGuire (1994). Computing markov-perfect nash equilibria: numerical implications of a dynamic differentiated product model. RAND Journal of Economics 25(4), 555-589.

Pogodzinski, J. M. and T. R. Sass (1991). Measuring the effects of municipal zoning regulations: A survey. Urban Studies 28(4), 597-621.

Powers, T. F. (1992). Introduction to management in the hospitality industry. New York: J. Wiley.

Quigley, J. M. (2007). Regulation and Property Values: The High Cost of Monopoly, pp. 46-66. Land Policies and Their Outcomes. Cambridge, MA: Lincoln Institute.

Ridley, D. B., F. A. Sloan, and Y. Song (2010). Retail zoning and competition. Duke University Working Paper.

Ryan, S. (2009). The costs of environmental regulation in a concentrated industry. MIT Working paper.

Sullivan, E. T. (2000). Antitrust regulation of land use: Federalism's triumph over competition, the last fifty years. Washington University Journal of Law and Policy 3, 473-512.

Train, K. (2003). Discrete choice methods with simulation. New York: Cambridge University Press.

Wu, J. and S.-H. Cho (2007). The effect of local land use regulations on urban development in the Western United States. Regional Science and Urban Economics 37(1), 69-86. 


\section{A Appendix A: Derivation of the Choice Probability (NOT FOR PUBLICATION)}

This appendix derives the choice probabilities when a hotel chain's deccision problem is written as

$$
\max \left(\Pi(1, \mathbf{s})+v_{1}, \Pi(0, \mathbf{s}), \Pi(-1, \mathbf{s})+v_{2}\right)
$$

While this model is quite similar to the standard multinomial logit model, the lack of stochastic shock in a particular choice (i.e., $a=0$ ) brings different forms of the choice probabilities. The derivation is quite similar to that of the standard multinomial logit model shown in, for example, Train (2003). For notational purpose, I first rewrite this problem as

$$
\max \left(g_{1}+v_{1}, g_{0}, v_{i 2}\right)
$$

where

$$
\begin{aligned}
& g_{1}=\Pi(1, \mathbf{s})-\Pi(-1, \mathbf{s}) \\
& g_{0}=\Pi(0, \mathbf{s})-\Pi(-1, \mathbf{s}) .
\end{aligned}
$$

The probability hotel chains choose no change is

$$
\begin{aligned}
\operatorname{Pr}(a=0) & =\operatorname{Pr}\left(g_{0}>v_{2} \text { and } g_{0}>g_{1}+v_{1}\right) \\
& =F\left(g_{0}\right) \cdot F\left(g_{0}-g_{1}\right) \\
& =\exp \left(-e^{-g_{0}}\right) \cdot \exp \left(-e^{-\left(g_{0}-g_{1}\right)}\right) \\
& =\exp \left(-e^{-g_{0}}\left(1+e^{g_{1}}\right)\right) .
\end{aligned}
$$

The probability that hotel chains choose closing a hotel is

$$
\begin{aligned}
\operatorname{Pr}(a=-1) & =\operatorname{Pr}\left(v_{2}>g_{0} \text { and } v_{2}>g_{1}+v_{1}\right) \\
& =\int_{-\infty}^{\infty} 1\left(v_{2}>g_{0}\right) \cdot F\left(v_{2}-g_{1}\right) d F\left(v_{2}\right) \\
& =\int_{-\infty}^{\infty} 1\left(v_{2}>g_{0}\right) \exp \left(-e^{-\left(v_{2}-g_{1}\right)}\right) \exp \left(-v_{2}\right) \exp \left(-e^{-v_{2}}\right) d v_{2} \\
& =\int_{g_{0}}^{\infty} \exp \left(-e^{-v_{2}}\left(e^{g_{1}}+1\right)\right) e^{-v_{2}} d v_{2} .
\end{aligned}
$$


Denoting $t=e^{-v_{2}}$, I have $d v_{2}=-\frac{d t}{e^{-v_{2}}}=-\frac{d t}{t}$.

$$
\begin{aligned}
\operatorname{Pr}(a=-1) & =\int_{g_{0}}^{0} \exp \left(-t\left(e^{g_{1}}+1\right)\right) t\left(-\frac{d t}{t}\right) \\
& =\int_{0}^{e^{-g_{0}}} \exp \left(-t\left(e^{g_{1}}+1\right)\right) d t \\
& =\left[\frac{e^{-t\left(e^{g_{1}}+1\right)}}{-\left(e^{g_{1}}+1\right)}\right]_{0}^{e^{-g_{0}}} \\
& =\left(1-e^{-e^{-g_{0}}\left(e^{g_{1}}+1\right)}\right) \cdot \frac{1}{e^{g_{1}}+1} \\
& =(1-\operatorname{Pr}(a=0)) \cdot \frac{1}{e^{g_{1}}+1} .
\end{aligned}
$$

Finally, the probability that hotel chains choose opening a new hotel (i.e., $a=1$ ) is

$$
\begin{aligned}
\operatorname{Pr}(a=1) & =1-\operatorname{Pr}(a=-1)-\operatorname{Pr}(a=0) \\
& =1-(1-\operatorname{Pr}(a=0)) \frac{1}{e^{g_{1}}+1}-\operatorname{Pr}(a=0) \\
& =(1-\operatorname{Pr}(a=0)) \cdot \frac{e^{g_{1}}}{e^{g_{1}}+1} .
\end{aligned}
$$

Summarizing the result, if $h \in\{1, \cdots, 6\}$,

$$
\left\{\begin{array}{l}
\operatorname{Pr}(a=-1)=\left(1-\exp \left(-e^{-g_{0}}\left(1+e^{g_{1}}\right)\right)\right) \cdot \frac{1}{e^{g_{1}}+1} \\
\operatorname{Pr}(a=0)=\exp \left(-e^{-g_{0}}\left(1+e^{g_{1}}\right)\right) \\
\operatorname{Pr}(a=1)=\left(1-\exp \left(-e^{-g_{0}}\left(1+e^{g_{1}}\right)\right)\right) \cdot \frac{e^{g_{1}}}{e^{g_{1}+1}}
\end{array}\right.
$$

or

$$
\left\{\begin{array}{l}
\operatorname{Pr}(a=-1)=(1-U(s)) \cdot \frac{1}{1+\exp (\Pi(1, \mathbf{s})-\Pi(-1, \mathbf{s}))} \\
\operatorname{Pr}(a=0)=\exp \left(-e^{-(\Pi(0, \mathbf{s})-\Pi(-1, \mathbf{s}))}\left(1+e^{\Pi(1, \mathbf{s})-\Pi(-1, \mathbf{s})}\right)\right) \\
\operatorname{Pr}(a=1)=(1-U(s)) \cdot \frac{\exp (\Pi(1, \mathbf{s})-\Pi(-1, \mathbf{s}))}{1+\exp (\Pi(1, \mathbf{s})-\Pi(-1, \mathbf{s}))}
\end{array}\right.
$$

where

$$
U(s)=\exp \left(-e^{-\Pi(0, \mathbf{s})}\left(e^{\Pi(-1, \mathbf{s})}+e^{\Pi(1, \mathbf{s})}\right)\right)
$$

If $\Pi(-1, \mathbf{s}) \rightarrow-\infty$ (i.e., $h=0)$, 


$$
\left\{\begin{array}{l}
\operatorname{Pr}(a=-1)=0 \\
\operatorname{Pr}(a=0)=\exp \left(-e^{\Pi(1, \mathbf{s})-\Pi(0, \mathbf{s})}\right) \\
\operatorname{Pr}(a=1)=1-\exp \left(-e^{\Pi(1, \mathbf{s})-\Pi(0, \mathbf{s})}\right) .
\end{array}\right.
$$

If $\Pi(1, \mathbf{s}) \rightarrow-\infty$ (i.e., $h=7$ ),

$$
\left\{\begin{array}{l}
\operatorname{Pr}(a=-1)=1-\exp \left(-e^{-(\Pi(0, \mathbf{s})-\Pi(-1, \mathbf{s}))}\right) \\
\operatorname{Pr}(a=0)=\exp \left(-e^{-(\Pi(0, \mathbf{s})-\Pi(-1, \mathbf{s}))}\right) \\
\operatorname{Pr}(a=1)=0 .
\end{array}\right.
$$




\section{B Appendix B: Recovering the Construction Cost of a Midscale Chain Hotel (NOT FOR PUBLICATION)}

This appendix describes the procedure I follow to calculate the construction cost of a midscale chain hotel in Texas from industry source. I limit my focus on Best Western and La Quinta since their websites provide detailed information (but not construction cost) about their prototype models. Calculation consists of three steps. I first estimate the total building square footage of their prototype hotels. I next estimate the square foot cost for hotel construction in Texas. Finally, I obtain a construction cost estimate from the product of these two numbers.

My calculation for the total building square footage of a Best Western hotel and La Quinta hotel relies on the brochures they put on their websites. Among several prototypes proposed by these two chains, I look at Classic Mid-Scale Prototype for Best Western ${ }^{26}$ and Design B Prototype for La Quinta ${ }^{27}$.

Best Western's floor plan shows the amount of area allocated to each function of a hotel (e.g, guest rooms and administrative). Although I am able to obtain the total building square footage of this prototype by summing up these numbers, I do not use this sum directly since this prototype seems to reflect higher standards imposed to newly constructed hotels only and hotels in my sample do not necessarily follow this higher standards. First, its prototype has more rooms than those in my sample (80 rooms vs 60 rooms). Second, this prototype reflects its minimum room size requirement imposed to only new hotels (312 square foot) than that imposed to existing hotels (200 square foot). Considering these facts, I consider a hotel that has 60 guest rooms of 280 square foot. Assuming the amount of areas used for other functions are not different between this prototype and existing hotels, I conclude that a total building square footage of a Best Western hotel during my sample period is 29,600 foot. Table 16 provides a breakdown of this calculation. For La Quinta, I use the total building square footage shown in the brochure since the capacity difference between this prototype and the sample median is relatively small (114 rooms vs 105 rooms) and the brochure does not provide the breakdown of this total building square footage anyway. As a result, I use 55,041 square foot for the total building square footage for a La Quinta hotel.I next calculate the square foot construction cost for a motel. RS-Means provides a square foot construction cost for various types of commercial buildings. Among them, I employ the one for a two to three story motel. To reflect locational difference of construction costs, I also employ Location Factors, a price index provided by RS-Means. Finally, I normalize

\footnotetext{
${ }^{26} \mathrm{http}: / /$ www.bestwesterndevelopers.com/resources/classic/AS1.00.pdf

${ }^{27}$ http://www.lq.com/lq/about/franchise/PrototypeGuide-B.pdf
} 
Table 16: Total Building Square Footage for a Best Western hotel

\begin{tabular}{llr}
\hline \hline \multicolumn{1}{c}{ Functions } & Area (Sq. Foot) \\
\hline Sixty Guest Rooms & & 16,800 \\
Guest Room Support & Corridors, Stairs, Guest Laundry & 4,741 \\
Administrative & Offices & 545 \\
Public Areas & Lobby, Business Center, Fitness Center & 4,415 \\
Back of House Areas & Employee Lounge, Linen, Storage & 3,099 \\
Total & & 29,600 \\
\hline
\end{tabular}

Notes: The average guest rooms size is assumed to be 280 squares foot.

this square foot cost to 2000 dollars by employing Turner Building Cost Index provided by Turner Construction. Following these steps, I obtain 81.3 dollar for square foot cost. ${ }^{28}$

Finally, I multiply the obtained square foot cost with the total building square footage. As a result, I obtain $\$ 2,407$ thousand dollars $(=81.3 \times 29,600)$ as an estimate for the total construction cost of a Best Western hotel and $\$ 4,505$ thousand dollars for that of a La Quinta hotel.

\footnotetext{
${ }^{28}$ The breakdown of this calculation is 147.75 dollar as a square footage construction cost, .790 as a location factor and .697 as Turner Building Cost Index. Rouding brings a slight difference between the product of these three numbers and the number shown in the text.
} 